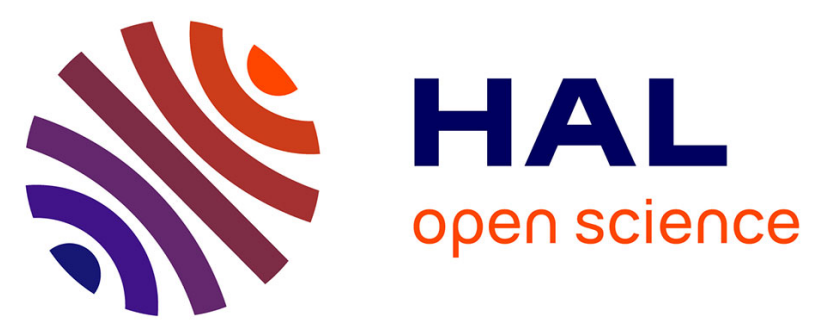

\title{
History of Chemical Routes towards Cyclic Non-Enzymatic Oxygenated Metabolites of Polyunsaturated Fatty Acids
}

Camille Oger, Claire Cuyamendous, Aurélien de La Torre, Mathieu Candy, Alexandre Guy, Valérie Bultel-Poncé, Thierry Durand, Jean Marie Galano

\section{To cite this version:}

Camille Oger, Claire Cuyamendous, Aurélien de La Torre, Mathieu Candy, Alexandre Guy, et al.. History of Chemical Routes towards Cyclic Non-Enzymatic Oxygenated Metabolites of Polyunsaturated Fatty Acids. Synthesis: Journal of Synthetic Organic Chemistry, 2018, 50 (17), pp.3257-3280. 10.1055/s-0036-1589540 . hal-02613521

\section{HAL Id: hal-02613521 \\ https://hal.umontpellier.fr/hal-02613521}

Submitted on 3 Jun 2021

HAL is a multi-disciplinary open access archive for the deposit and dissemination of scientific research documents, whether they are published or not. The documents may come from teaching and research institutions in France or abroad, or from public or private research centers.
L'archive ouverte pluridisciplinaire HAL, est destinée au dépôt et à la diffusion de documents scientifiques de niveau recherche, publiés ou non, émanant des établissements d'enseignement et de recherche français ou étrangers, des laboratoires publics ou privés. 


\section{History of Chemical Routes towards Cyclic Non-Enzymatic Oxygenated Metabolites of Polyunsaturated Fatty Acids}

\author{
Camille Oger \\ Claire Cuyamendous \\ Aurélien de la Torre \\ Mathieu Candy \\ Alexandre Guy \\ Valérie Bultel-Poncé \\ Thierry Durand \\ Jean-Marie Galano
}

Institut des Biomolécules Max Mousseron, IBMM, Université de Montpellier, CNRS, ENSCM, Faculté de Pharmacie, 15 Av. Ch. Flahault, BP 14491, 34093 Montpellier Cedex 05, France Jean-marie.galano@umontpellier.fr

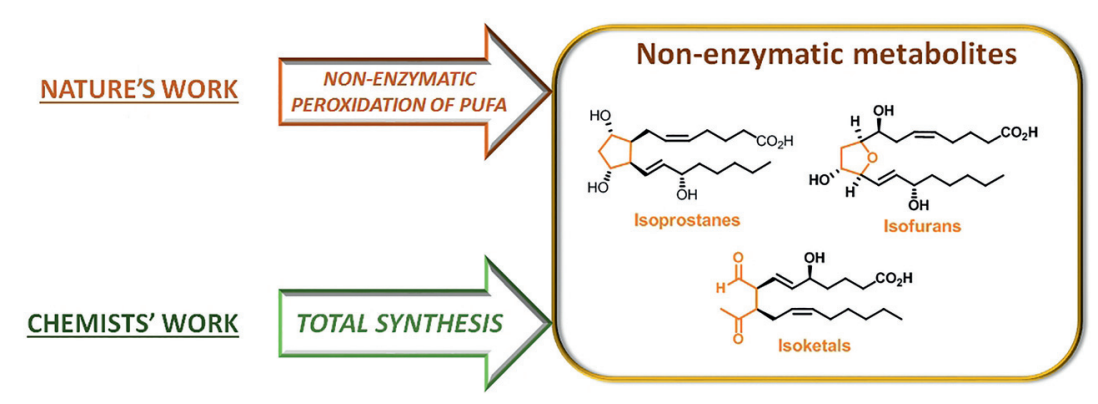

\section{Introduction}

In our everyday diet, polyunsaturated fatty acids (PUFAs) of the omega- 3 and omega- 6 types play important roles in human health, from the composition of membranes to the generation of oxygenated metabolites (also called oxylipins). Some of the most famous oxylipins are biosynthesized by enzymes such as the cyclooxygenases (COXs), which for example generate the prostaglandins (PG), the hormone-like natural compounds. The main substrate for this synthesis is the omega-6 PUFA arachidonic acid (AA).

In 1990, a hidden group of oxylipins generated by nonenzymatic reactions, gained importance as mediators of biological responses. These compounds are structurally related to the PGs and were named isoprostanes (IsoPs). ${ }^{1}$

This non-enzymatic mechanism involves free radicals (also called reactive oxygen or nitrogen species for ROS or RNS) that are produced in our body, and as such, the IsoPs generated by this process have become reliable biomarkers of the generation of ROS in humans. The biological excessive production of ROS, not controlled by the body defenses, is called oxidative stress, and leads to bimolecular damage such as lipid, protein, and DNA alterations.

Since the discovery of isoprostanes, other families of non-enzymatic oxygenated PUFA (NEO-PUFA) have been highlighted. This review will focus essentially on cyclic NEO-PUFA, and more especially the work of organic chemists who dedicate their research activities to the synthesis and comprehension of such compounds. It will also familiarize the reader with their biological actions and biomarker roles.

This manuscript is divided into three parts. At first in Section 2, a brief presentation of the cyclic NEO-PUFA will be necessary to understand their origin, followed by a more complete description of the structures of the diverse families of cyclic non-enzymatic PUFA metabolites and their no- 


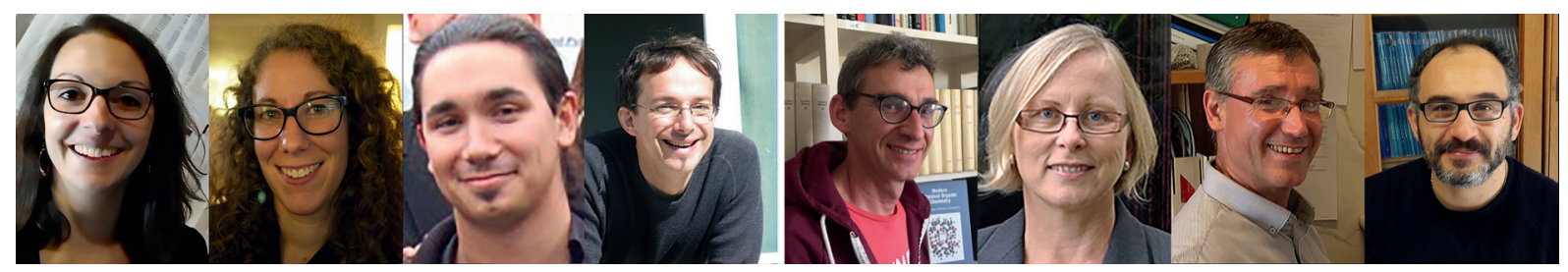

Camille Oger was born in Saint-Gaudens (France) in 1984. She studied chemistry at Paul Sabatier University in Toulouse and University of Paris VI. She then moved to Montpellier and received her Ph.D. in the field of total synthesis of neuroprostanes at the University of Montpellier II, in 2010. She carried out postdoctoral work with Prof. Ilan Marek at the Technion-Israel Institute of Technology and was promoted assistant professor at the University of Montpellier in 2011 and promoted associate professor in 2016. Her research interest includes the development of new strategies toward the synthesis of bioactive lipids, the quantification of such metabolites, and the discovery of biological activities.

Claire Cuyamendous was born in Orléans (France) in 1987. She studied organic chemistry at the National Graduate School of Chemistry of Montpellier (France), where she received her graduation and master degree in 2012. In 2015, she obtained her Ph.D. at the University of Montpellier in the field of total synthesis of phytofurans, under the supervision of Dr. Camille Oger and Dr. Jean-Marie Galano. She achieved a postdoctoral study at the center for biodiscovery in Victoria University of Wellington and worked with Dr. Joanne Harvey and Dr. Paul Teesdale-Spittle on the total synthesis of Pateamine A. Currently she is ATER 'assistant associate professor' in the laboratory of methodology of organic synthesis in Le Mans.

Aurélien de la Torre was born in 1988 in Montpellier, France. He graduated in Chemical Engineering from the Ecole Nationale Supérieure de Chimie de Montpellier and obtained a research M.Sc. degree in organic chemistry from the University of Montpellier II in 2011. In 2014, he received his Ph.D. from the University of Montpellier I, under the supervision of Dr. Jean-Marie Galano and Dr. Camille Oger, working on the total synthesis of isofuranoid compounds. After two years as a postdoctoral fellow in the group of Prof. Nuno Maulide in the University of Vienna, Austria, and one year with Prof. Ilan Marek at the Technion-Israel Institute of Technology, he was appointed Chargé de Recherche CNRS in October 2018 in the group of Prof. Cyrille Kouklovsky at the University Paris-Sud.

Mathieu Candy studied at the Aix Marseille Université (AMU) where he obtained his Ph.D. in 2010 under the supervision of Prof. Jean-Marc Pons and Prof. Cyril Bressy. His thesis topic was focused on hidden symmetry in total synthesis a desymmetrization of meso-diols. He then joined the group of Prof. Dr. Carsten Bolm in Aachen, Germany as a Humboldt postdoctoral researcher, where he worked on the chemistry of sulfondiimines. Back in France, he joined the group of Prof. J. M. Campagne and then Dr. T. Durand both in Montpellier as post-doctoral researcher working on total synthesis of natural products. He then completed an industrial project in Toulouse, France in the group of Dr. Y. Genisson and worked for DACD Company in St Marcel lès Valences (France).

Alexandre Guy was born in Albi (France) in 1970. He studied organic chemistry at the National Graduate School of Chemistry of Mulhouse (France), where he received his graduation and master degree in 1993. In 1998, he obtained his Ph.D. at the University of Montpellier in the field of total synthesis of isoprostanes under the supervision of Prof. Jean-Claude Rossi and Dr. Thierry Durand. At present he is an engineer at CNRS. His research interests are in the areas of organic synthesis and medicinal chemistry, particularly on total synthesis of oxygenated derivatives obtained in vivo from non-enzymatic peroxidation of PUFAs.

Valérie Bultel-Poncé was born in Montpellier and received her undergraduate education at Montpellier University. She obtained her Ph.D. in 1991 at Perpignan University and she did postdoctoral studies at Muséum National d'Histoire Naturelle in Paris, in the field of natural products chemistry. At present she is an engineer at Montpellier University. Her research interests are in the areas of organic synthesis and medicinal chemistry, particularly on total synthesis of oxygenated derivatives obtained in vivo from non-enzymatic peroxidation of PUFAs, like isoprostanes, neuroprostanes.

Thierry Durand studied chemistry at University of Paris VI, and then moved to Montpellier and received his Ph.D. at University of Montpellier I in 1990. After a postdoctoral training at Florida Institute of Technology in Melbourne, USA, with Joshua Rokach, he became Chargé de Recherche CNRS at the University of Montpellier I in 1991. He finished his Habilitation in 1996 and became Directeur de Recherche CNRS in 2002. He is a group leader at the Institute of Biomolécules Max Mousseron. His research interests include the total synthesis of oxygenated cyclic and acyclic metabolites of polyunsaturated fatty acids, mainly leukotrienes, iso-, phyto-, and neuroprostanes, as well as dihydroxylated PUFAs and more recently lipophenols, and the understanding of the role of such bioactive lipids and lipophenols by developing collaborations with chemists, biochemists, biologists, and clinicians over the word.

Jean-Marie Galano studied chemistry at Paul Cézanne University Marseille and obtained his Ph.D. under the supervision of Honoré Monti in 2001. He then moved to the University of Oxford to pursue a postdoctoral fellowship with David H. Hodgson on the development of new methods for the total synthesis of natural products. In October 2005 he joined the CNRS as a Chargé de Recherche at the University of Montpellier. His research focuses on the total synthesis and discovery of new lipid metabolites, and to discover their potential implications in human health. 
menclature. The second part (Section 3) will focus on the synthetic strategies developed to access all families of oxylipins of interest. It should be mentioned that this review will only cover work between 2008 and 2017, starting from the previous and complete review by Jahn, Galano, and Durand. ${ }^{2}$ Finally, a short third part (Section 4) will present in a brief and non-exhaustive fashion the recent biological discoveries associate with them.

\section{Non-Enzymatic Metabolites of PUFAs}

\subsection{Where Do They Come From?}

During the 1960s and 1970s, structurally closed compounds (one stereocenter difference) were found by the work of Nugteren, ${ }^{3}$ Pryor, ${ }^{4}$ and Porter ${ }^{5}$ following the autooxidation of arachidonoyl-containing lipids, which were termed prostaglandin-like compounds at the time. It was only in the 1990s that a group showed more interest in these prostaglandin-like compounds assuming that they may also be produced in vivo via a mechanism independent of the catalytic activity of the cyclooxygenase enzyme (COX). Morrow, Roberts, and Harris looked at lipid extracts from humans using GC/MS negative-ion chemical ionization and revealed the formation of prostaglandins isomers, ${ }^{6}$ which was confirmed by the correlation with the peroxidation of arachidonic acid induced by $\mathrm{CCl}_{4}$ administration to rats. ${ }^{1}$ Thanks to the mass monitoring, the biosynthetic pathway as well as the structure of the prostanoids was revealed, and the name isoprostane (IsoP) was chosen. The main differences between PGs and IsoPs are understandable by their biosynthesis. Indeed, while IsoPs are formed in the lipid membrane as a phospholipid (the PUFA still attached to the phosphorus head), PGs are made via the cy- clooxygenases (COXs) from arachidonic acid release from the phospholipid by phospholipases. Two major structural differences between the two of them are that IsoPs generated are racemic and the configuration of the two side chains is mainly cis, while only trans configuration is generated for PG and only one enantiomer is observed (Figure 1).

Taking a deeper look inside the membrane revealed the biosynthesis of the IsoPs (Scheme 1) following reaction with free radicals. To make a long biosynthesis short, free radicals first attack the bis-allylic positions of the PUFA, ${ }^{8}$ and Scheme 1 represents the abstraction at the $\mathrm{C} 13$ position, although other bis-allylic positions can also be attacked (C7 and C10). But once $\mathrm{H}$-atom abstraction occurs, a cascade of oxidation proceeds that includes the insertion of two molecule of oxygen, two consecutive 5-exo-trig cyclizations, and further reductions leading to racemic IsoPs. In this example, the 15-series of IsoP is generated where the allylic alcohol is on C15. In contrast to prostaglandins, for which the $\mathrm{H}$-atom abstraction only proceeds on $\mathrm{C} 13$ of $\mathrm{AA}$, other IsoPs can be generated after $\mathrm{C} 7 \mathrm{H}$-atom abstraction (to make the 5-series of IsoP) and at the $\mathrm{C} 12$ position (to make both the 8-series and 12-series of IsoPs).

Since the discovery of IsoPs and thanks to the syntheses of pure synthetic standards, the field of non-enzymatic oxygenated lipid metabolites has continued to expand, 2,7,8 and many more oxylipins have been found, and will be presented hereby with a focus on the cyclic ones.

\subsection{Why Are They Interesting Metabolites?}

An organism produces a myriad of enzymatically driven lipid metabolites for multiple reasons, but the non-enzymatic oxygenated metabolites formed are much less studied. Indeed, for a long time this domain of interest suffered from the dogma that relevant metabolites are only pro-

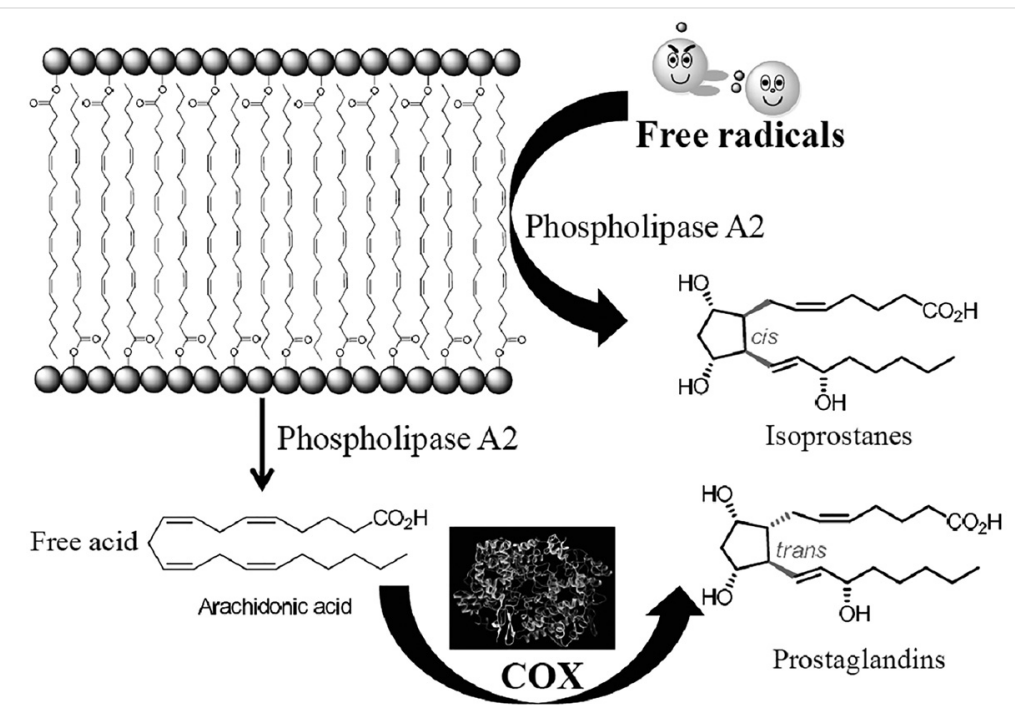

Figure 1 Biosynthesis of prostaglandins (PGs) versus isoprostanes (IsoPs) 

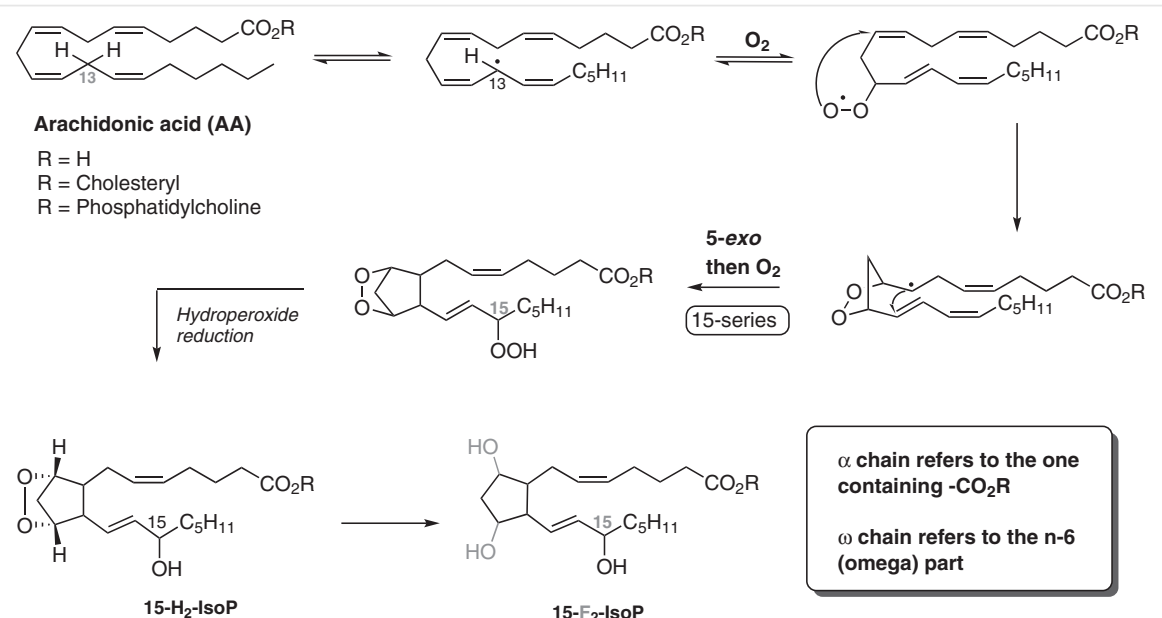

Scheme 1 Representative mechanism of isoprostane formation via free radicals

duced by enzymes. However, two ideas have now emerged. First, as a burst of free radicals is generated under oxidative stress conditions, these NEO-PUFA can be considered as oxidative stress biomarkers, and nowadays the isoprostanes are considered as 'gold standard' biomarkers for systemic oxidative stress. ${ }^{9}$ Second, is the expanding role of NEOPUFA as mediators of physiological and pathophysiological diseases, such as vasoconstrictors, ${ }^{10}$ platelet activity modulator, ${ }^{11}$ or more recently as new anti-arrhythmic compounds. ${ }^{12}$ For more details, the reader is encouraged to read recent specialized reviews for further knowledge. ${ }^{13-15}$

\subsection{A Huge Family of Natural Compounds}

\subsubsection{Presentation of All Families}

In this part of our story we will explore the chemical structures of the main cyclic NEO-PUFA. This descriptive part is necessary for the chemist to clearly feel the differences between all the metabolites, as well as the huge family of metabolites they represent in vivo.

\subsubsection{Isoprostanoids}

In the family of isoprostanoids, those from arachidonic acid (AA, C20:4 n-6) were the first to be discovered thanks to the considerable efforts made on prostaglandins. Similar to PG, IsoPs are composed of a cyclopentane ring and two lateral chains named alpha $(\alpha)$ and omega $(\omega)$. The $\alpha$-chain is the one bearing the carboxylic acid moiety whereas the $\omega$-chain is the one with the $(Z)$-double bond referring to the lipid nomenclature ( $n-6$ or $n-3)$. Then, the cyclopentane ring may have different oxidation states, i.e. dihydroxylated (referred to as F-IsoPs, Figure 2), hydroxy ketone (referred to as D- and E-IsoPs, Figure 2 ), and $\alpha, \beta$-unsaturated ketone (referred to as A-, B-, L-, and J-IsoPs, Figure 2).
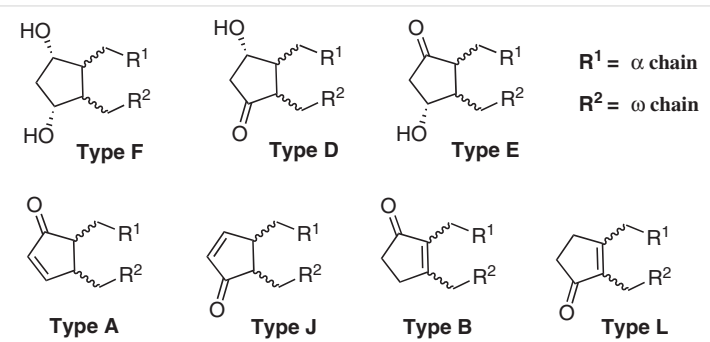

Figure 2 Representation of the different oxidation states of the cyclopentane ring in isoprostanoids

Keeping in mind that the biosynthesis of isoprostane leads to different lateral chains depending on the carbon where the hydrogen atom is abstracted (Section 2.1, 15-, 5-, $12-$, and 8-series), and that several PUFA exist in our cell membranes, the family of isoprostanoids is gigantic. Table 1 summarize the different isoprostanoids and their structures: the parent PUFA, the given name, the number of carbons and unsaturations on the lateral chains, the number of lateral chain structures and isomers leading to isoprostanoids structure (cis relationship between lateral chains as well as between hydroxy groups on the cyclopentane), and finally the total number of isomers (only given for the Ftype of isoprostanoids). Thinking of all the other type of isoprostanoids that are formed in vivo (Figure 2), this clearly shows how total synthesis is important for this research area, and some of them still need to be synthesized (highlighted in grey in Table 1).

\subsubsection{Isofuranoids}

In 2002, a new family of oxygenated PUFA metabolites was discovered by Roberts and co-workers. ${ }^{20}$ The mass analysis showed the formation of new compounds with superior mass of $16 \mathrm{Da}$, and the structure was assigned as a 2,3,5-trisubstituted furan ring carrying a hydroxy group 
Table 1 Isoprostanoids Family

\begin{tabular}{|c|c|c|c|c|c|}
\hline PUFA & Metabolite name (abbreviation) & $\begin{array}{l}\text { Number of carbon at- } \\
\text { oms (unsaturations on } \\
\text { the chains) }\end{array}$ & $\begin{array}{l}\text { Number of lateral } \\
\text { chain structures } \\
\text { (regioisomers) }\end{array}$ & $\begin{array}{l}\text { Number of isomers lead- } \\
\text { ing to isoprostanoids }\end{array}$ & $\begin{array}{l}\text { Total number of metabo- } \\
\text { lites (only F-type) enantio- } \\
\text { mers included }\end{array}$ \\
\hline ALA (C18:3 n-3) & phytoprostane (PhytoP) ${ }^{16}$ & $18(1)$ & 2 & 8 & 32 \\
\hline AA $(C 20: 4 n-6)$ & isoprostane $(\mathrm{IsoP})^{1}$ & $20(2)$ & 4 & 8 & 64 \\
\hline EPA (C20:5 n-3) & isoprostane (IsoP) ${ }^{17}$ & $20(3)$ & 6 & 8 & 96 \\
\hline AdA (C22:4n-6) & dihomo-isoprostane (Dihomo-IsoP) ${ }^{18}$ & $22(2)$ & 4 & 8 & 64 \\
\hline DPA (C22:5n-6) & neuroprostane (NeuroP $\left.{ }_{\text {DPAn-6}}\right)$ & $22(3)$ & 6 & 8 & 96 \\
\hline DPA (C22:5n-3) & neuroprostane (NeuroP $\left.{ }_{\text {DPAn-3 }}\right)$ & $22(3)$ & 6 & 8 & 96 \\
\hline DHA (C22:6n-3) & neuroprostane (NeuroP) ${ }^{19}$ & $22(4)$ & 8 & 8 & 128 \\
\hline
\end{tabular}

${ }^{a}$ Grey highlighting indicates proposed metabolites that have not yet been discovered in vivo.

and two lateral chains, and was named isofuran (IsoF) (Scheme 2). Two families co-exist in the IsoFs, the alkenylIsoFs and the enediol-IsoFs. The enediol-IsoFs have two hydroxy groups on the same lateral chain whereas the alkenyl-IsoFs have one hydroxy on the $\alpha$-chain and one hydroxy on the $\omega$-chain (Scheme 2). Two biosynthetic pathways were proposed,,$^{20}$ however an alternative route was proposed in 2008 by Jahn, Durand, and Galano ${ }^{2}$ that also explains the formation of both alkenyl and the enediol IsoFs (Scheme 2).
In comparison with the isoprostanoids, this new family was shown to be formed preferentially when the oxygen tension is higher. Under $21 \%$ of oxygen tension, isoprostanoids production continues to increase together with IsoFs, but above that level IsoPs formation remains stable, while the IsoFs continues to increase until $100 \%$ of $\mathrm{O}_{2}$ tension. This discovery is of great interest as some diseases are associated with more or less oxygen tension. For example, the oxygen tension is higher in Parkinson's disease than in Alzheimer's. Thus, the isofuranoids may represent a new class of biomarkers that are more specific to certain diseases.
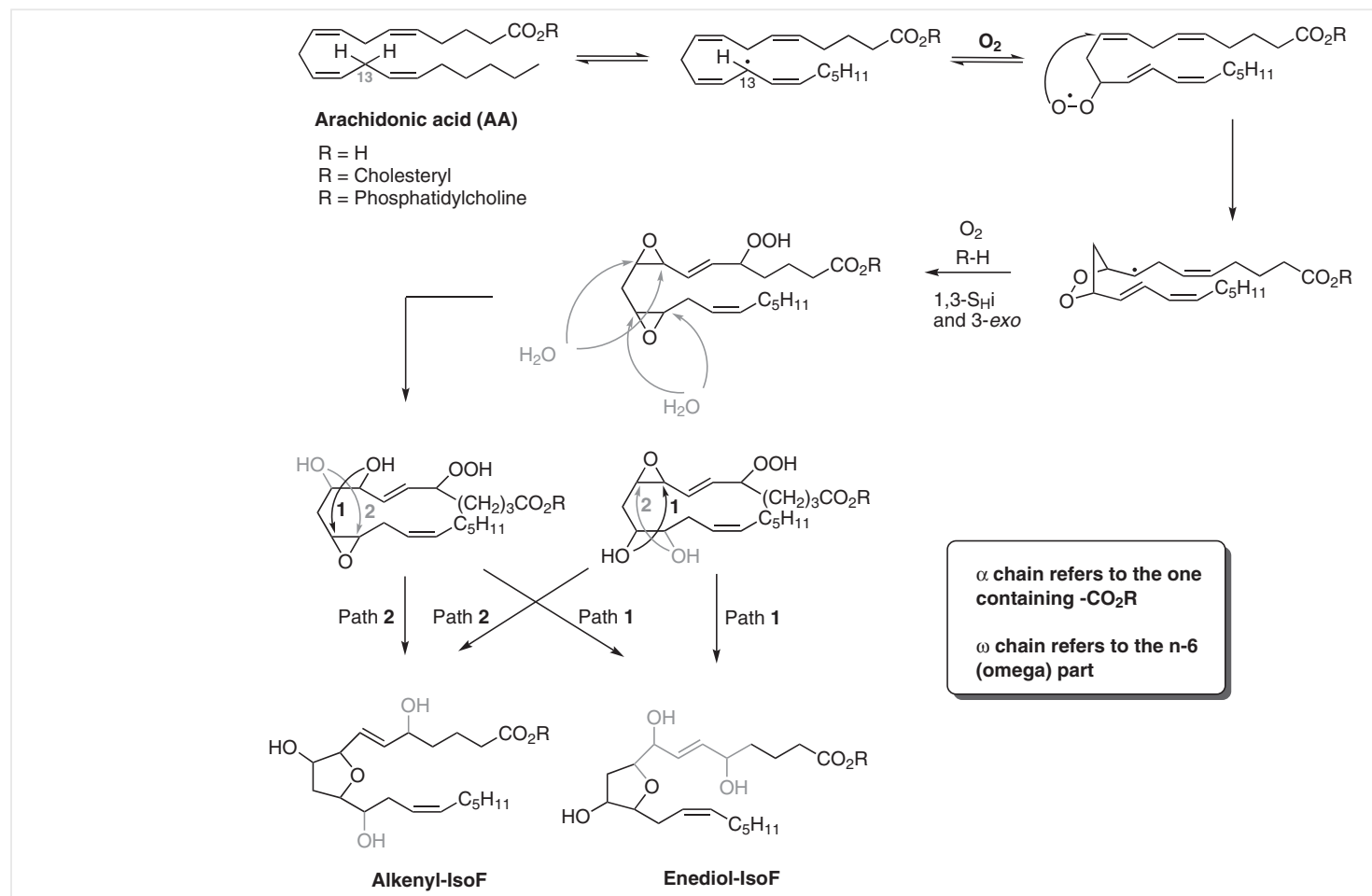

Scheme 2 A rapid look at the proposed free radicals induced the peroxidation of arachidonic acid into isofurans (IsoFs) 
Table 2 Isofuranoids Family ${ }^{a}$

\begin{tabular}{|c|c|c|c|c|c|}
\hline PUFA & Metabolite name (abbreviation) & $\begin{array}{l}\text { Number of carbon atoms } \\
\text { (unsaturations on the } \\
\text { chains) }\end{array}$ & $\begin{array}{l}\text { Number of lateral chain } \\
\text { structures (alkenyl, enedi- } \\
\text { ol, and regioisomers) }\end{array}$ & $\begin{array}{l}\text { Number of isomers } \\
\text { (per regioisomer) }\end{array}$ & Total number of isomers \\
\hline ALA (C18:3 n-3) & phytofuran (PhytoF) ${ }^{21}$ & $18(1)$ & 4 & 32 & 128 \\
\hline AA $(C 20: 4 n-6)$ & isofuran $(\mathrm{IsoF})^{20}$ & $20(2)$ & 8 & 32 & 256 \\
\hline EPA $(C 20: 5 n-3)$ & isofuran (IsoF) & $20(3)$ & 12 & 32 & 384 \\
\hline AdA (C22:4n-6) & dihomo-isofuran (Dihomo-IsoF) 22 & $22(2)$ & 8 & 32 & 256 \\
\hline DPA (C22:5n-6) & neurofuran (NeuroF ${ }_{\text {DPAn-6 }}$ ) & $22(3)$ & 12 & 32 & 384 \\
\hline DPA (C22:5 n-3) & neurofuran (NeuroF ${ }_{\text {DPAn-3 }}$ ) & $22(3)$ & 12 & 32 & 384 \\
\hline DHA (C22:6n-3) & neurofuran (NeuroF) ${ }^{23}$ & $22(4)$ & 16 & 32 & 512 \\
\hline
\end{tabular}

${ }^{a}$ Grey highlighting indicates proposed metabolites that have not yet been discovered in vivo.

At present, only four classes of isofuranoids have been discovered from the common PUFAs. Table 2 sums up the isofuranoids and their structures, and reflects the enormous number of isomers as well as the work which still needs to be done in this field to demonstrate their formation in vivo (in grey are highlighted the proposed metabolites not yet discovered in vivo) and their potent biological properties.

\subsubsection{Isoketals}

At the end of the 1990s, a family of PUFA metabolites was found mainly as their adduct forms such as lactam, pyrrole. ${ }^{24-27}$ The structure of the metabolites was assigned to be the same lateral chains as the IsoPs, however with a methyl ketone and an aldehyde function instead of the IsoP ring. The reactive aldehyde group thus reacts with surrounding free $\mathrm{NH}_{2}$ of proteins to form the corresponding pyrrole and/or lactam adducts. The structure of the metabolites is close to that of the levuglandins (derived from PGs) and thus they are named isolevuglandins or isoketals (IsoKs). The biosynthesis of IsoKs is common to that of IsoPs until the hydro-endoperoxides intermediate (Scheme 3), where it decomposes under basic conditions to generate IsoKs.
Since the discovery of IsoKs, only two classes have been studied; the IsoKs from arachidonic acid and NeuroKs from docosahexaenoic acid (DHA, C22:6 n-3). Despite this fact, IsoKs appear to be potent biomarkers of oxidative stress in inflammatory pathways, immune responses, ${ }^{15,28}$ and thus need to be further studied.

\subsubsection{Nomenclature of These Metabolites}

A huge number of non-enzymatic metabolites are formed in vivo, and even if their structures can sometimes appear similar, they are all distinct metabolites with their own biosynthetic route and biological interest. Thus, nomenclatures were developed for each family of these metabolites. This review uses and describes only IUPAC nomenclature.

\subsubsection{Isoprostanoids}

After their discovery, some time was needed to work on a comprehensive nomenclature that can be used for all classes of isoprostanoids, and in 1997, two distinct nomenclatures were simultaneously proposed by Rokach ${ }^{29}$ and

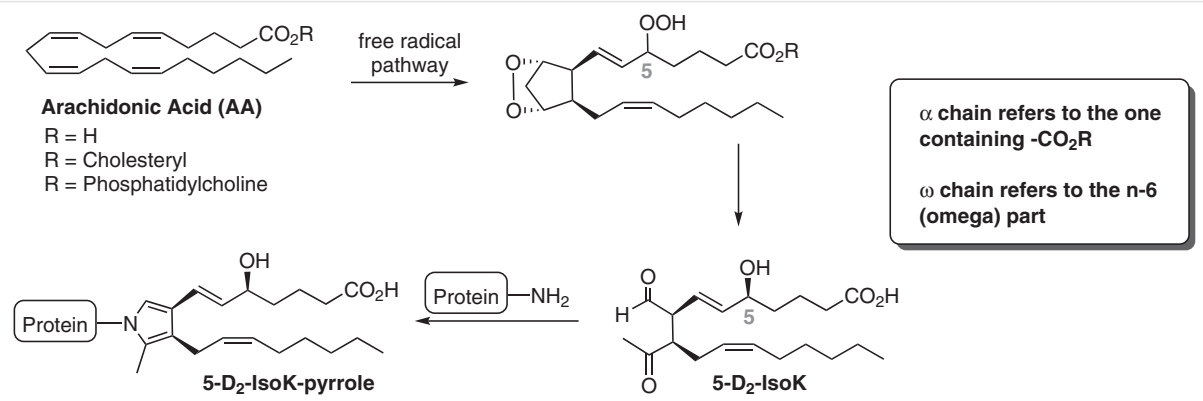

Scheme 3 A brief look at the proposed free radicals induced the peroxidation of arachidonic acid into isoketals (IsoKs) 
Roberts. ${ }^{30}$ The nomenclature proposed by Roberts was the one accepted by IUPAC and here we give one molecule as a brief, but representative, example.

The molecule given in Figure 3 is named $4-\mathrm{F}_{4 \mathrm{t}}$-neuroprostane ( $\left.4-\mathrm{F}_{4 \mathrm{t}}-\mathrm{NeuroP}\right)$. The first digit, $4-\mathrm{F}_{4 \mathrm{t}} \mathrm{-}$-NeuroP refers to the positional number of the carbon of the allylic alcohol, with $\mathrm{C} 1$ as the carboxylic acid. Then, after the dash, the ring substitution pattern of isoprostanoid is given. In $4-\mathrm{F}_{4 \mathrm{t}}-\mathrm{Neu}-$ roP, type-F denotes that the cyclopentane bears two hydroxy groups (see Figure 2), with the first subscript as the total number of double bonds on the lateral chains ( 4 in this case as this metabolite arises from DHA, see Table 1 ), and second as the letter $t$ (trans) for the relative configuration between the $\alpha$-chain and the adjacent hydroxy group on the cyclopentane. Finally, the name $4-\mathrm{F}_{4 \mathrm{t}}$-NeuroP finishes with the abbreviation for the isoprostanoid (IsoP, dihomoIsoP, NeuroP, Table 1). It should be mentioned that by default the absolute configuration of the allylic alcohol at C4 is $S$. Thus, if this stereogenic center is reversed (i.e., $R$ ), the term epi should be affixed at the beginning of the name and preceded by position (e.g., 4-epi-4- $\mathrm{F}_{4 \mathrm{t}}-\mathrm{NeuroP}$ ). Also, in the presence of the enantiomer of this NeuroP, the term ent should be written at the beginning of the name (e.g., ent-4$\mathrm{F}_{4 \mathrm{t}}$-NeuroP). Two more examples of names are given in Figure 3.
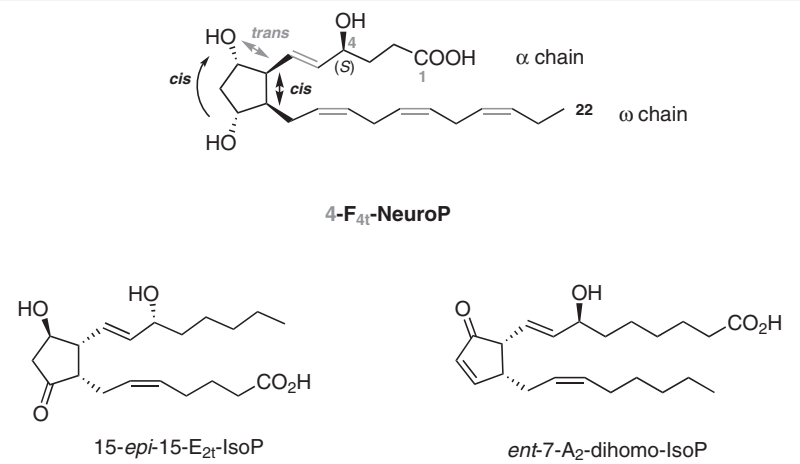

Figure 3 Examples for the nomenclature of isoprostanoids

\subsubsection{Isofuranoids}

Nomenclature was proposed for isofurans ${ }^{31}$ in 2004, only two years after their discovery. The proposed nomenclature is mainly based on the relative orientation of the side chains and substituents, allows the differentiation of each isomeric structures. Again we will discuss the nomenclature for a single example, AC- $\Delta^{8}-11$-NeuroF (Figure 4).

As for isoprostanoids, the numbering starts from the carboxylic acid as $\mathrm{C} 1$. Then, by default the first ring carbon atom (here C11) as well as the carbons bearing hydroxy groups $(\mathrm{OH})$ on the side chains have $S$-configuration. Now, the nomenclature begins with the relative orientation of the alkyl chains AC- $\Delta^{8}-11-$ NeuroF: $\operatorname{syn}(\mathrm{S})$ or anti (A), and is followed by the relative orientation of the ring hydroxy
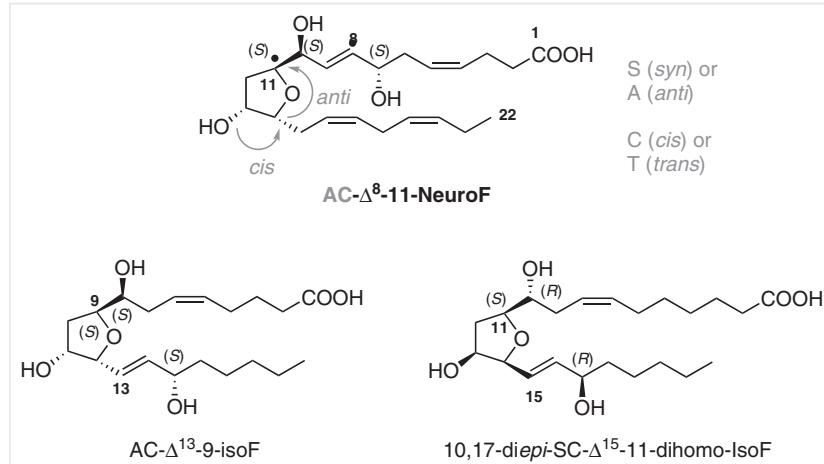

10,17-diepi-SC- $\Delta^{15}$-11-dihomo-IsoF

Figure 4 Examples for the nomenclature of isofuranoids

group and the adjacent alkyl chain: cis $(\mathrm{C})$ or trans $(\mathrm{T})$. Then after the dash, AC- $\Delta^{8}-11-$ NeuroF, $\Delta^{8}$ denotes the positional number of the carbon of the $E$ double bond, and this is followed, by the positional number of the first ring carbon atom, AC- $\Delta^{8}-11-$ NeuroF. As for isoprostanoids, the abbreviation of the metabolites is affixed at the end, AC- $\Delta^{8}-11-\mathrm{Neu}-$ roF (see Table 2). Caution is needed regarding the default configurations (first ring carbon atom and the carbon atoms bearing hydroxy groups on the side chain). The term epi, preceded by the carbon number is used if the configuration of the hydroxy group is inverted. However, in this nomenclature, if the first ring carbon atom has the default $S$ configuration, the term ent is written at the beginning of the nomenclature and thus all the hydroxy groups on the side chains are then considered $(R)$ as default. Two other examples are given in Figure 4.

\subsubsection{Isoketals}

Thanks to the work on PGs and derivatives and the recent nomenclature for isoprostanoids, two nomenclatures were rapidly proposed for isolevuglandins/isoketal. The first one refers to the levuglandins (PG derivatives) and uses the term isolevuglandins (IsoLG) ${ }^{24}$ when the second one is closest to the isoprostanoids and used the term isoketal. ${ }^{26}$ Despite the fact that the term isoketal is misleading, the second nomenclature, which is closest to the IUPAC rules, will be used and presented in this review (Figure 5).
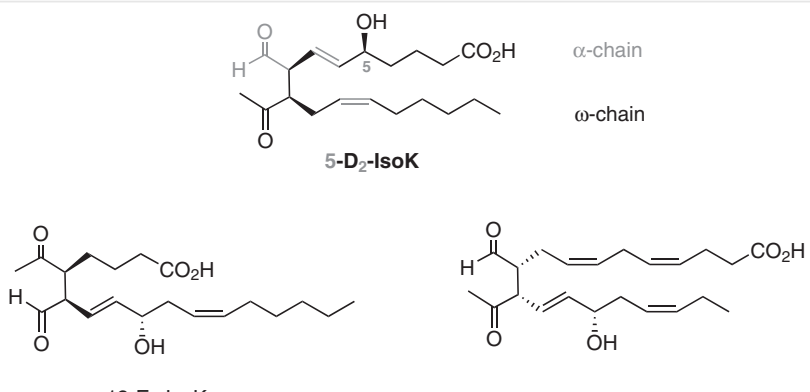

12-E-IsoK ent-17-epi-17- $\mathrm{D}_{4}-$ NeuroK

Figure 5 Examples for the nomenclature of isoketals 
Table 3 Isoketals Family ${ }^{2}$

\begin{tabular}{|c|c|c|c|c|c|}
\hline PUFA & Metabolite name (abbreviation) & $\begin{array}{l}\text { Number of carbon atoms } \\
\text { (unsaturations on the chains) }\end{array}$ & $\begin{array}{l}\text { Number of lateral chain } \\
\text { structures (regioisomers) }\end{array}$ & $\begin{array}{l}\text { Number of isomers } \\
\text { leading to isoketals }\end{array}$ & $\begin{array}{l}\text { Total number of metabo- } \\
\text { lites (for D- and E-types) }\end{array}$ \\
\hline $\operatorname{ALA}(C 18: 3 n-3)$ & phytoketal (PhytoK) & $18(1)$ & 2 & 4 & 16 \\
\hline AA $(C 20: 4 n-6)$ & isoketal $\left(\right.$ IsoK) ${ }^{24}$ & $20(2)$ & 4 & 4 & 32 \\
\hline EPA $(C 20: 5 n-3)$ & isoketal (IsoK) & $20(3)$ & 6 & 4 & 48 \\
\hline AdA $(C 22: 4 n-6)$ & dihomo-isoketal (Dihomo-IsoK) & $22(2)$ & 4 & 4 & 32 \\
\hline DPA (C22:5n-6) & neuroketal (NeuroK DPAn-6) ) & $22(3)$ & 6 & 4 & 48 \\
\hline DPA (C22:5n-3) & neuroketal (NeuroK DPAn-3 ) & $22(3)$ & 6 & 4 & 48 \\
\hline DHA (C22:6 n-3) & neuroketal (NeuroK) ${ }^{26,27}$ & $22(4)$ & 8 & 4 & 64 \\
\hline
\end{tabular}

a Grey highlighting indicates proposed metabolites that have not yet been discovered in vivo.

The example in Figure 5 is called $5-\mathrm{D}_{2}$-IsoK. The first digit, $5-\mathrm{D}_{2}$-IsoK, refers to the positional number of the carbon of the allylic alcohol. The, after the dash, the letter, 5$\mathrm{D}_{2}$-IsoK shows the type of the isoketal which arises from the PGs/IsoPs (Figure 2), in this case, the aldehyde function is on the same side to the $\alpha$-chain hence it is a D-type, and as for isoprostanoids, the subscript number gives the number of double bonds present on the lateral chains. Finally, the abbreviation regarding the PUFA parent metabolite 5$\mathrm{D}_{2}$-IsoK concludes this nomenclature (Table 3). As for isoprostanoids, the absolute configuration of the allylic alcohol is $S$ by default and in the presence of the epimer the term epi should be affixed at the beginning of the name and preceded by the position. The same thing should be done in the presence of the enantiomer (ent as a prefix).

\section{Total Synthesis Strategies}

\subsection{Isoprostanoids}

Since the discovery of IsoPs, several research groups have worked on synthetic strategies, and two main strategies stand out; (1) a biomimetic approach by designing the skeleton (complete or partial) then ring closure; (2) make the cyclic core and introduce the lateral chains one after the other. ${ }^{2,13}$

The approach of Jahn and Dinca is closely related to the biosynthesis of isoprostanoids as it relies on a radical cyclization to obtain the cyclopentane core, followed by an oxygenation to introduce the allylic alcohol moiety (Scheme 4). ${ }^{32}$ It presents the advantage of having one of the two lateral chains already introduced before the cyclization. The target needs to be known from the start of the synthesis.

The cyclization step proceeds between the dianion produced from compound $\mathbf{3}$ in the presence of LDA as a base and $\mathrm{LiCl} / \mathrm{HMPA}$, and ferrocenium hexafluorophosphate. The cyclization occurs preferentially through a Beckwith-Houk transition state to form the cycle and a resonant radical anion successively trapped by TEMPO (2,2,6,6-tetramethylpiperidin-1-oxyl) to perform the oxidation and insert the alcohol group on the lateral chain. The diastereomeric ratio is moderate $(\mathrm{dr}=1.7: 1)$, but with a good yield and the facility to scale up the reaction to gram amounts. It should be mentioned that the same key step can be used for the preparation of PGs by changing the base to a Grignard reagent ( $t$-BuMgCl, LDA, HMPA), which reverses the diastereo-

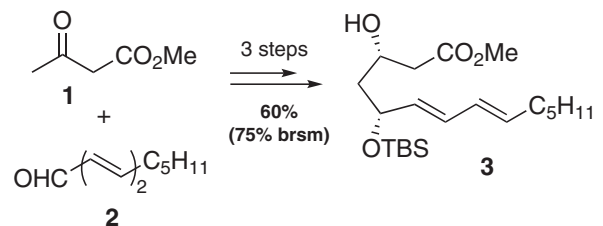

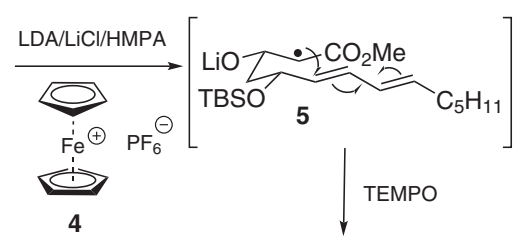

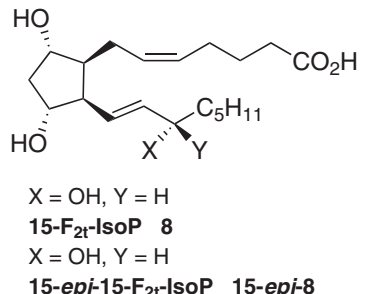

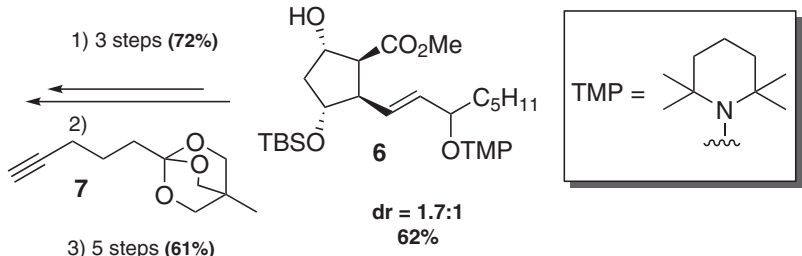




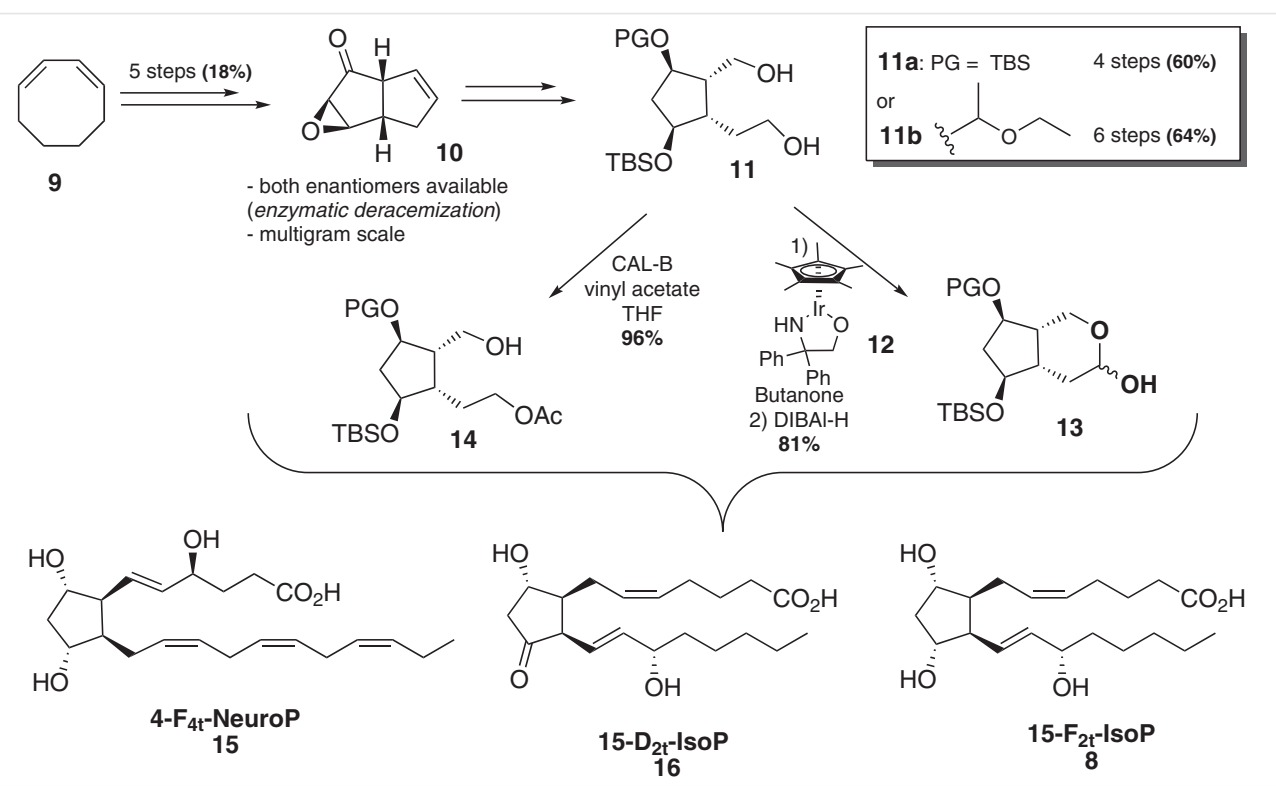

Scheme 5 Synthetic strategy of the Durand, Galano, and Oger group to access D-, E-, and F-isoprostanoids; CAL-B = Candida antarctica lipase B

selectivity. Then, the preparation of $15-\mathrm{F}_{2 \mathrm{t}}$-IsoP was completed by introduction of the $\alpha$-chain by alkynylation using alkynylithium ortho ester $\mathbf{7}$ in good yield. The reduction of the triple bond was performed as the last step using Lindlar reagent. Note, both $\mathrm{C} 15$ epimers of the $15-\mathrm{F}_{2 \mathrm{t}}$-IsoP were obtained after oxidative cleavage of the TMP group, reduction of the resulting enone $(\mathrm{dr}=1.7: 1)$, and separation of both epimers. This strategy also allowed, for example, the preparation of $15-\mathrm{E}_{2 \mathrm{t}}$-IsoP ${ }^{33}$ and $\mathrm{F}$ - and E-type of phytoprostanes $^{34}$ albeit as their methyl esters (which could be problematic for a final-step saponification because of known epimerization next to the ketone).

The strategy of the Durand, Galano, and Oger group relies on obtaining a functionalized cyclic intermediate where the lateral chains can be introduced sequentially (Scheme 5). ${ }^{35}$ The main advantage that a common skeleton $\mathbf{1 0}$ or $\mathbf{1 1}$ is created that can be prepared and stored, then the lateral chains can be introduced depending on the target. The second advantage is the ease with which the configurations are introduced solely based on the bicyclic shape on the scaffold.

Compound 10, the common intermediate in this strategy, is obtained in five steps starting from cycloocta-1,3-diene in good yields for both enantiomers, and on a gram scale. Based on this skeleton, the lactol intermediate $\mathbf{1 3}$ orthogonally protected or not, is obtained in 6 or eight steps in good yields ( $52 \%$ and $49 \%$, respectively). ${ }^{35}$ The lateral chains are then introduced by Horner-WadsworthEmmons (HWE) and Wittig reactions with the corresponding $\beta$-ketophosphonate and phosphonium salt. Depending on the structures of the targets, the ylide partner in the Wittig reaction can be sensitive and will react at the same temperature as the hemiacetal moiety. Thus, another route was envisioned using an enzymatic regioselective protection of the 1,5-diol in order to obtained a monoacetylated alcohol 14. ${ }^{36}$ This new intermediate offered the opportunity to introduce the lateral chain again by Wittig reaction, however on a more reactive aldehyde species. The gain of flexibility thanks to the two scaffolds (lactols 13 and monoacetates 14) allows the preparation of E-, D-, and F-isoprostanoids. Thanks to this strategy several new PUFA-metabolites were prepared. ${ }^{37-40}$

Unfortunately, this strategy was not convenient to access the L- and B-types of phytoprostanes. Therefore, the group developed a new strategy, starting from cyclopentane-1,3-dione (17). ${ }^{41}$ Reductive alkylation at C2 of the cyclopentane-1,3-dione (17) permitted installation of the first lateral chain as well as an exocyclic vinyl double bond; the latter is needed for the installation of the second lateral chain using cross-metathesis (Scheme 6).

Vidari and co-workers reported an even more general access to PhytoP in 2015. ${ }^{42}$ They could access both B- and Ltype and the 9- and 16-series; 16(RS)- $\mathrm{L}_{1}$-PhytoP 32 exemplifies their strategy based on chemoselective lithiation to introduce the side chains (Scheme 7). Starting from OTBSprotected 2-iodo-3-bromocyclopentenol 26, the regioselective I/Li exchange followed by formylation furnished the aldehyde functionality ready for HWE reaction or alternatively in two steps via a Meyer-Schuster rearrangement of propargyl alcohol derivative easier to handle than the aldehyde intermediate. Subsequently, the enone $\mathbf{2 8}$ was converted through four standard reactions, in $66 \%$ overall yield, into vinyl bromide 29, ready for the successive SuzukiMiyaura reaction. Organoborane $\mathbf{3 0}$ was then reacted with bromide $\mathbf{2 9}$ under Johnson conditions, to deliver adduct $\mathbf{3 1}$ 

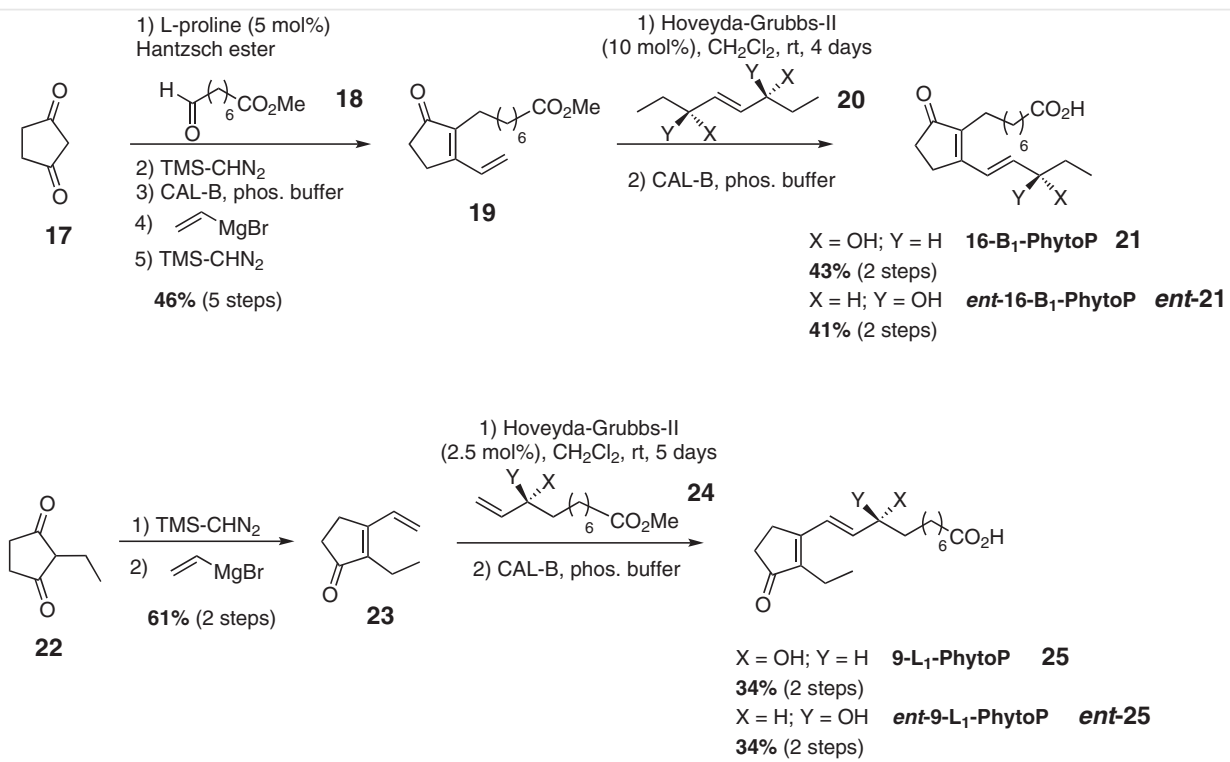

Scheme 6 Synthetic strategy of the Durand, Galano, and Oger group to access B- and L-phytoprostanes

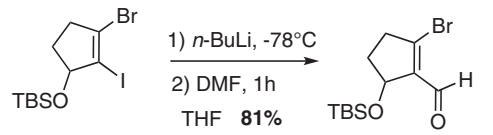

26

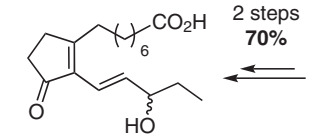

16(RS)-L $\mathrm{L}_{1}$-PhytoP $(R S)-32$

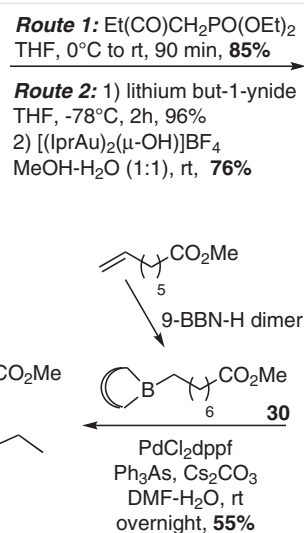

31

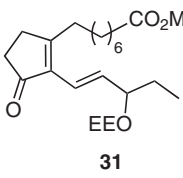

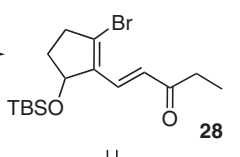
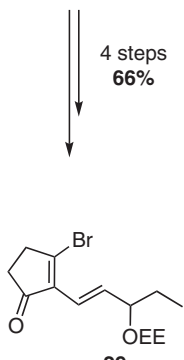

29

Scheme 7 General strategy for B-and L-phytoprostane by Vidari and co-workers

in $55 \%$ yield. The synthesis was then completed by deprotection and hydrolysis of the carboxylic acid methyl ester by using a biocatalytic method.

Another approach to $16-\mathrm{B}_{1}$-PhytoP and $9-\mathrm{L}_{1}$-PhytoP was also described in 2013 by Riera and co-workers using the Julia olefination of a formylcyclopentenone, which was prepared by intermolecular Pauson-Khand reaction. ${ }^{43}$

In recent years a new class of isoprostanoids has caught the attention of organic chemists, the epoxy-isoprostanes (epoxy-IsoPs). Epoxy-IsoPs were discovered at the end of the 1990s by oxidation of 1-palmitoyl-2-arachidonoyl-snglycero-phosphocholine. ${ }^{44}$ The cyclopentane ring substitution follows the same rules as the common isoprostanoids, and A- and E-types of epoxy-IsoPs were detected. These compounds are described as their acid form and named EI (epoxyisoprostane) for the E-type (Scheme 8) and EC (epoxycyclopentane) for the A-type, or described as their pal- mitoylphosphocholine form and called PEIPC for the E-type and PECPC for the A-type. It should be mentioned that several epoxy regioisomers can be produced in vivo (e.g., 5,6epoxy-IsoPs or 14,15-epoxy-IsoPs).

The synthesis of epoxy-IsoPs has been predominantly investigated by four groups; Jung, ${ }^{45,46}$ Kobayashi, ${ }^{47}$ Carreira, ${ }^{48,49}$ and $\mathrm{Lu}^{50}$ with several modifications of their strategies over the years.

In 2005, the Jung group developed a strategy toward $E_{2}-$ epoxy-IsoPs linked to palmitoylphosphocholine (PEIPC 39), ${ }^{51}$ which has been improved over the years. ${ }^{45,46}$ The strategy started by the synthesis of cyclic intermediate $\mathbf{3 4}$ from achiral diacetate $\mathbf{3 3}$ in seven steps and $\mathbf{8 7 \%}$ global yield (Scheme 9). ${ }^{51,52}$ The insertion of the first chain $(\omega$ chain) was then realized in four steps, including the protection of the alcohol group on the cyclopentane ring as the tert-butyldiphenylsilyl (TBDPS) ether. The second lateral 

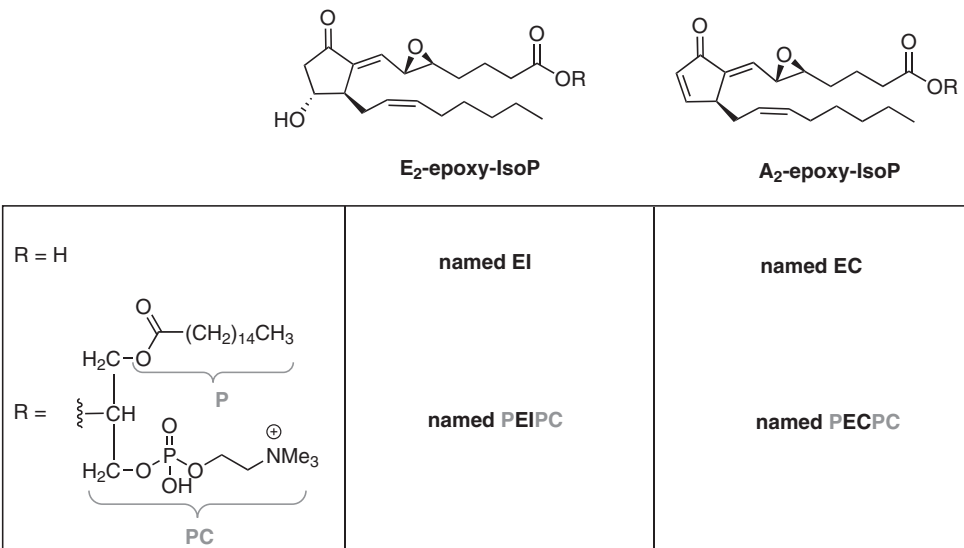

$A_{2}$-epoxy-IsoP

named EC

named $\mathrm{PEC} P \mathrm{C}$

Scheme 8 Presentation of the epoxy-IsoPs, type A- and E
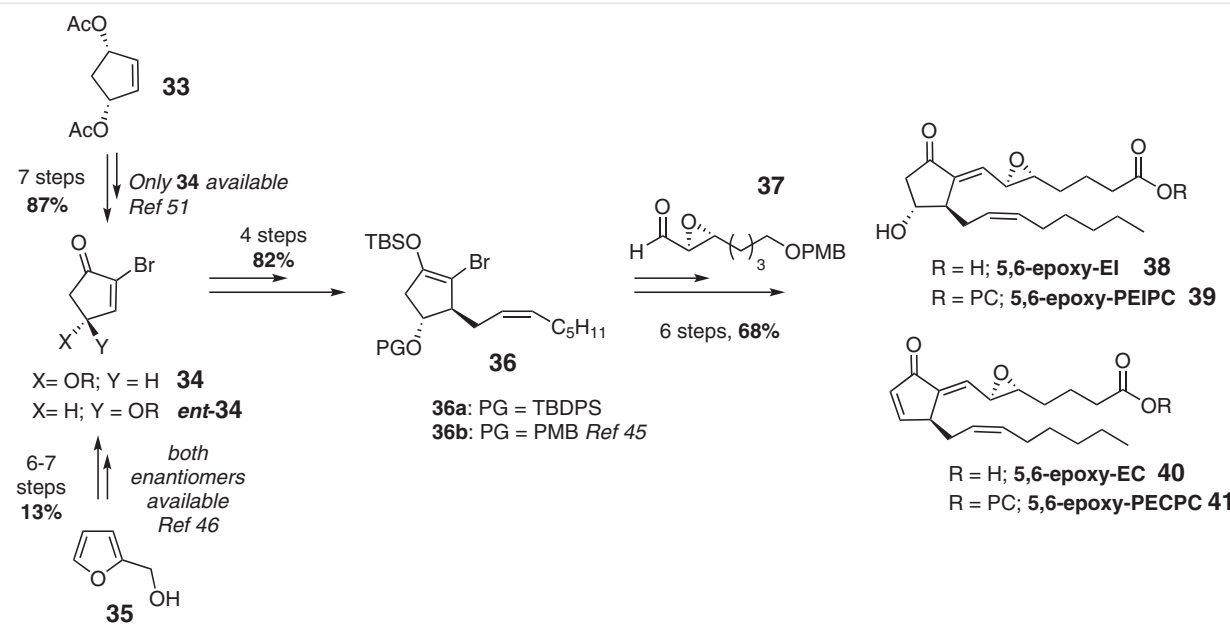

Scheme 9 Syntheses of epoxy-IsoPs by the Jung group

chain was then inserted using a coupling reaction between the corresponding vinyllithium of intermediate $36 \mathbf{a}$ and epoxy-aldehyde 37. The deprotection of the TBDPS ether remained tricky as classical TBAF/THF conditions at $0{ }^{\circ} \mathrm{C}$ produced only EC $\mathbf{4 0}$ metabolite in $90 \%$ yield. The addition of acetic acid provided both EI $\mathbf{3 8}$ and EC $\mathbf{4 0}$ in 40\% and 53\% isolated yields, respectively. The synthesis of PEIPC 39 was thus achieved by the coupling of lyso-PC prior to the deprotection of the TBDPS ether using TBAF/THF, $0{ }^{\circ} \mathrm{C}$ conditions. PEIPC 39 and PECPC 41 were obtained in a 1:3 ratio and separated using preparative HPLC.

These underwhelming results on silylated protecting group deprotection led the Jung group to some improvements in their synthetic strategy. In 2008, the TBDPS ether was replaced by the 4-methoxybenzyl ether (PMB) (compound $\mathbf{3 6 b}$ ), which avoids the elimination reaction leading to PECPC 41 and produced only PEIPC 39 metabolite. ${ }^{45}$ Then, in 2013, the preparation of intermediate 34 was changed. Started from furfuryl alcohol 35, it included an enzymatic resolution to obtain both enantiomers 34 and ent-
$34{ }^{46}$ This change permits the synthesis of four out of eight stereoisomers of EI metabolite, as well as their evaluation on human aortic endothelial cells showing the anti-inflammatory effect of such metabolites. Also, the preparation of intermediate $\mathbf{3 6}$ was slightly changed to simplify the synthesis.

The Kobayashi group worked on the synthesis of epoxyIsoPs for several years and, in 2005, they developed a strategy towards $\mathrm{A}_{2}$-type as the free acid or palmitoylphosphocholine ester (Scheme 10, A). ${ }^{53,54}$ Compound 44, obtained from the $(1 R)$-isomer of monoacetate $\mathbf{4 2}$ in seven steps and $55 \%$ yield, includes the first lateral chain ( $\omega$-chain) and permitted the introduction of the second one ( $\alpha$-chain) by an aldol reaction with corresponding epoxy-aldehyde. In their first attempt, they chose to have an ester moiety at the end of the intermediate and prepared several stereoisomers, ${ }^{53}$ while this ester group was changed for a PMB ether in another study. ${ }^{54}$ Thanks to this strategy, they succeeded in the preparation of the 5,6-epoxy-EC $\mathbf{4 0}$ and PECPC 41. A slight structural change of intermediate $\mathbf{4 6}$ to install a different 


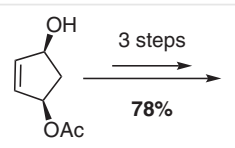

42

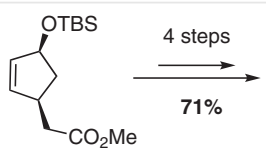

43

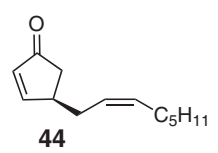

A)

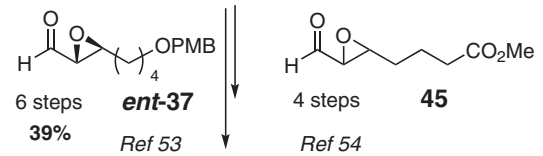

Ref 54

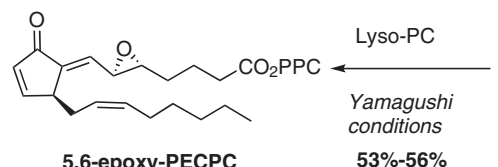

41
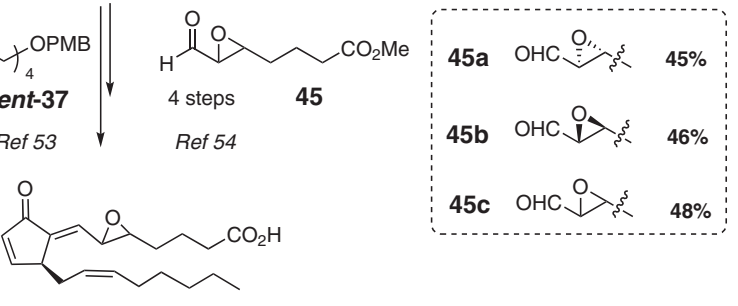

5,6-epoxy-EC

40

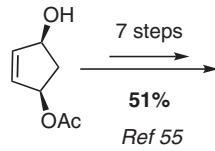

42

B)

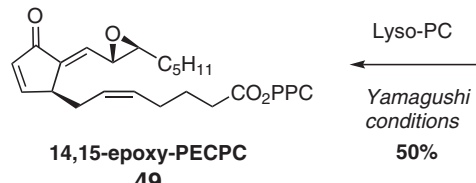

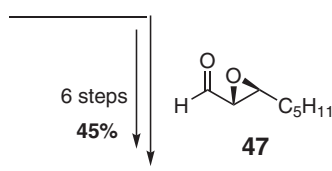

46

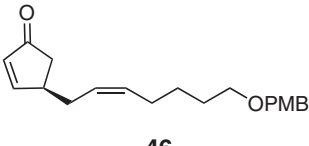

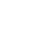

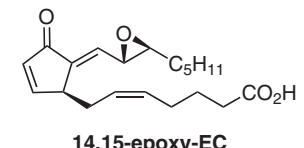

48

Scheme 10 Synthetic strategy of the Kobayashi group towards $A_{2}$-epoxy-IsoPs

chain (this time $\alpha$-chain) was also realized (Scheme 10, B), ${ }^{54}$ according to their previous results ${ }^{55}$ on the total synthesis of PG, allowing access to 14,15-epoxy-EC 48 and PECPC 49.

The Kobayashi group used a similar pathway for the preparation of the acetylenic analogue of $\mathrm{A}_{2}$-epoxy-IsoPs (Scheme 11) which can be hydrogenated at the end of the synthesis to obtain the natural metabolite. ${ }^{56}$ This pathway leaves the door open also to the synthesis of labeled metabolites such as tritiated or deuteriated as proposed by the authors.
Finally, the Kobayashi group turned its attention to $\mathrm{E}_{2}-$ type of epoxy-IsoPs and modified their strategy (Scheme 12) ${ }^{47}$ Starting from the same monoacetate intermediate $\mathbf{4 2}$, 11 steps are required to access the more advanced intermediate 52, including a PMB-protected alcohol on the cyclopentane, the first lateral chain containing a triple bond, as well as a bromine atom needed for directing the subsequent aldol reaction. Indeed, after a thorough optimization for the bromination and aldol reaction conditions, the PMB ether of 5,6- $\mathrm{E}_{2}$-epoxy-IsoP $\mathbf{5 4}$ was obtained after a further seven steps and in $35 \%$ yield.

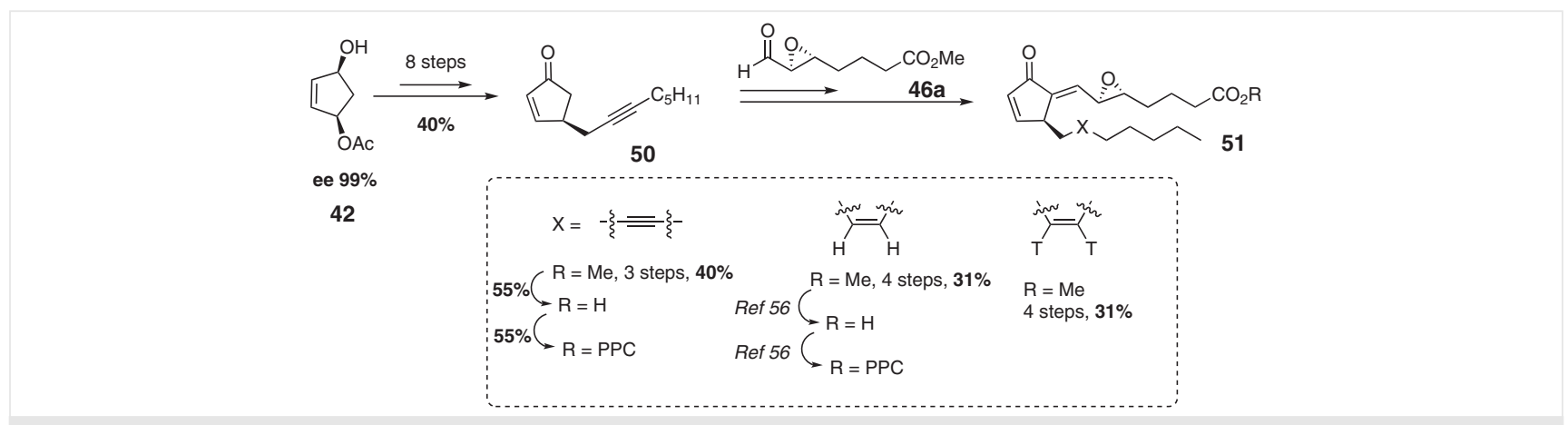

Scheme 11 Modifications for the synthesis of analogues 

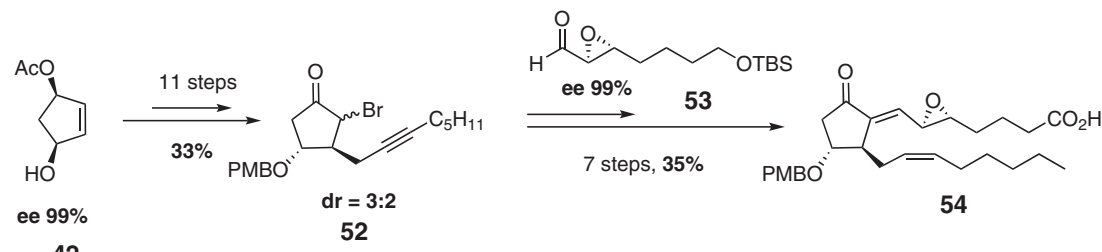

Scheme 12 Strategy towards $E_{2}$-epoxy-IsoPs

More recently in 2013, the Carreira group developed a chemical route toward epoxy-IsoP metabolites (Scheme 13). ${ }^{48}$ The strategy involved as a key step a $\mathrm{CH}$-insertion reaction for the creation of the cyclic core. The intermediate $\mathbf{5 6}$ for this key step is obtained in four steps from commercially available (Z)-dec-4-enal (55) in $45 \%$ global yield and $92 \%$ ee. The $\mathrm{CH}$-insertion step was promoted by rhodium catalysis; using $\left[\mathrm{Rh}_{2}(\mathrm{esp})_{2}\right]$ catalyst gave $\mathbf{5 9}$ with a good diastereomeric ratio (4:1) and with a cis relationship between OTES and the alkyl chain, which was further improved by using $\left[\mathrm{Rh}_{2}(\mathrm{~S}-\mathrm{PTAD})_{4}\right]$ catalyst, to $9: 1$ and in $71 \%$ yield. The following decarboxylation step allowed the separation of both diastereomers prior to an elimination step to provide the same intermediate $\mathbf{4 4}$ that was obtained by the Kobayashi group in good yield. An additional three steps gave access to pivotal intermediate $\mathbf{6 0}$ and then epoxy-IsoPs $\mathbf{4 0}$ or its palmitoylphosphocholine derivative $\mathbf{4 1}$ could be obtained in good yield.

An interesting possibility explored by the Carreira group was the transformation of cyclopentenone $\mathbf{6 0}$ into hydroxycyclopentanone $\mathbf{3 8}$ in three steps (epoxidation, $\mathrm{SmI}_{2}$ mediated opening, then enzymatic hydrolysis). This allowed the syntheses of EI $\mathbf{3 8}$ and PEIPC $\mathbf{3 9}$ in low yields. This powerful strategy was then employed by them for the preparation of epoxy-IsoP analogues (Scheme 14), by changing intermediate $\mathbf{5 6}$ for the preparation of $\mathbf{4 4}$ and aldehyde $\mathbf{4 6 a} .{ }^{49,57}$ The synthesis of these analogues highlighted the potent anti-inflammatory activity of potential metabolite lactone $\mathbf{6 1 .}$

Linked to their work on organocatalysis, the $\mathrm{Lu}$ and Weng group in 2015 used their expertise for the synthesis of the methyl ester of 5,6-epoxy- $\mathrm{A}_{2}$-IsoP $60 .{ }^{50}$ The precursor

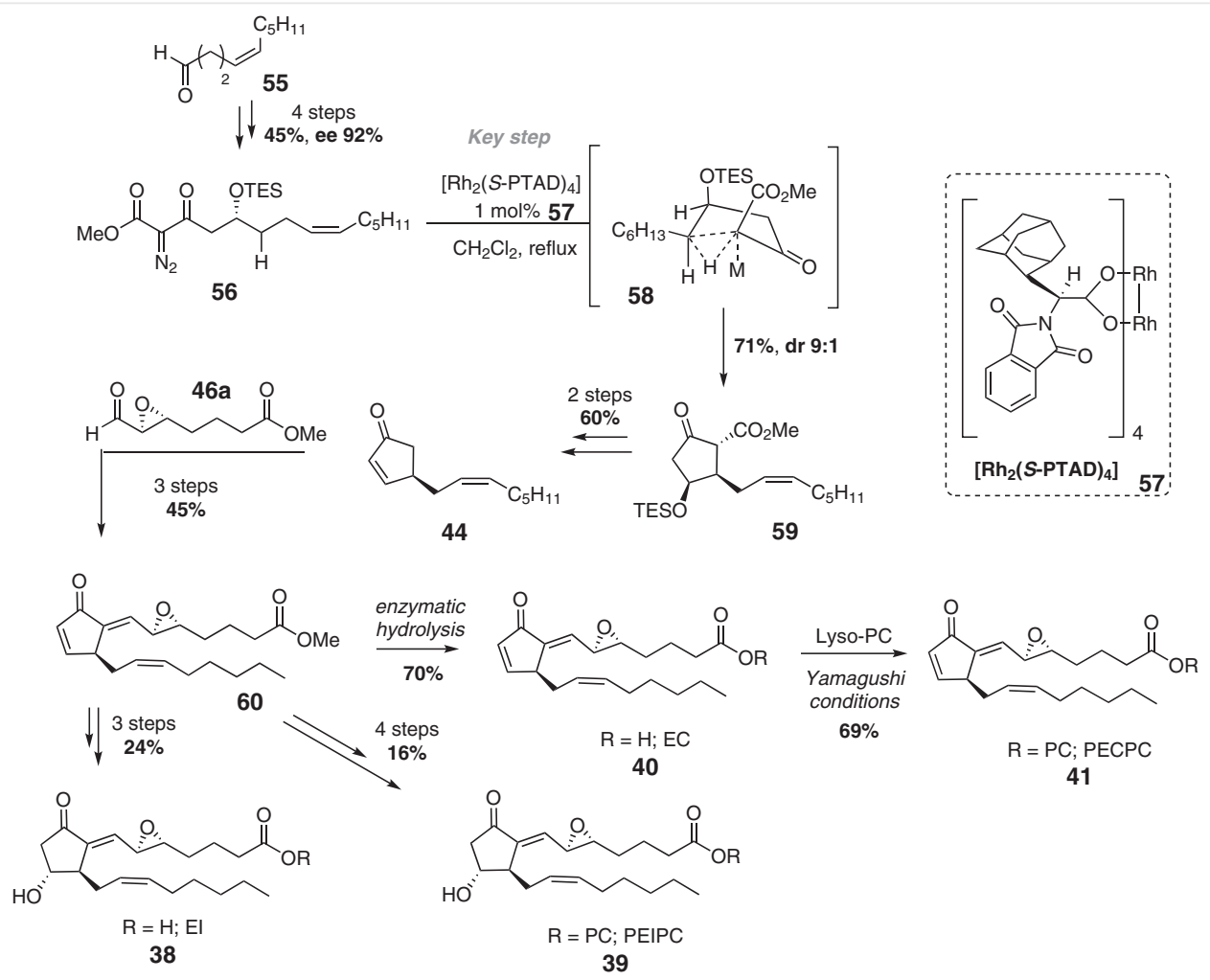

Scheme 13 Syntheses of epoxy-IsoPs and analogues by the Carreira group 


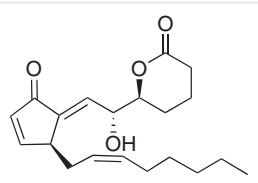

61

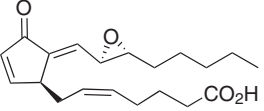

14,15-diepi-48

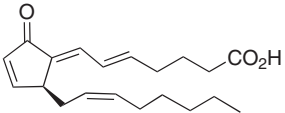

62

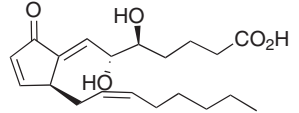

63

Scheme 14 Epoxy-IsoP analogues obtained by Carreira group

$\mathbf{6 8}$ of the cyclic shape of the molecule is obtained by two key steps, an organocatalyzed asymmetric Michael addition using a diarylprolinol silyl ether and an intramolecular aldol reaction, while the chains were introduced by Wittig and aldol reactions (Scheme 15). Asymmetric Michael addition and Wittig reaction to give $\mathbf{6 8}$ can also be nicely realized in a one-pot sequence with an increase of the global yield (69\% vs 62\%) albeit with a slight decrease of the diastereomeric ratio (from 85:15 to 73:27) and 96\% ee. Methyl ester decarboxylation and the removal of dimethyl acetal was also realized one-pot to provide the required compound 69 for the intramolecular aldol reaction, with a slight erosion of the enantiomeric ratio (90\% ee). The aldol reaction was optimized as racemization occurred under classical basic conditions. The best conditions were using $\mathrm{KOH}$ as the base in the presence of $\mathrm{N}$-benzyl-cinchoninium chloride and gave the known intermediate $\mathbf{4 4}$ in low yield (30\%) together with the $\alpha, \beta, \gamma, \delta$-unsaturated ketone byproduct (33\%). Only a small decrease of the enantiomeric excess was observed ( $87 \%$ ee vs $90 \%$ ee). The methyl ester of 5,6-epoxy$\mathrm{A}_{2}$-IsoP 60 was finally obtained after a further three steps, and to date it represents the shortest route to this compound.

\subsection{Isofuranoids}

The relevance of isofuranoids in the oxylipin field has attracted large interest from various research groups as important targets for total synthesis programs. Indeed, in 2004 , only two years after their discovery in 2002, the Taber group described the first total synthesis of a mixture of epimeric (on the side chain hydroxy group) enantiopure alkenyl IsoF. ${ }^{58}$ The strategy relies on the formation of the THF ring by a cascade epoxide cyclization $\mathbf{7 2}$ to $\mathbf{7 3}$, followed by the introduction of the lateral chains as organometallic species added to the epoxide and aldehyde functionalities (Scheme 16). In 2009, they were able to control the stereochemistry of the last asymmetric carbon by a slight modification of the substrate. ${ }^{59}$ The $\alpha$ lateral chain insertion by HWE olefination gives the possibility to reduce the enone stereoselectively. The strategy of the Taber group is also efficient for the synthesis of enediol IsoFs. In 2006, the total synthesis of the first enediol IsoF was achieved following the same key steps starting from substrate containing the $\alpha$ side chain. ${ }^{60 a}$ While the approach of the Taber group allowed the synthesis of two different alkenyl and one enediol IsoFs, the use of organometallic species for the introduction of the lateral chains appears to be less suitable for the synthesis of more sensitive structures such as NeuroFs. ${ }^{60 \mathrm{~b}}$

Following the discovery of NeuroF in 2007, the need for development of flexible and divergent strategies was obvious at the time. With this intention, in 2013 the Zanoni

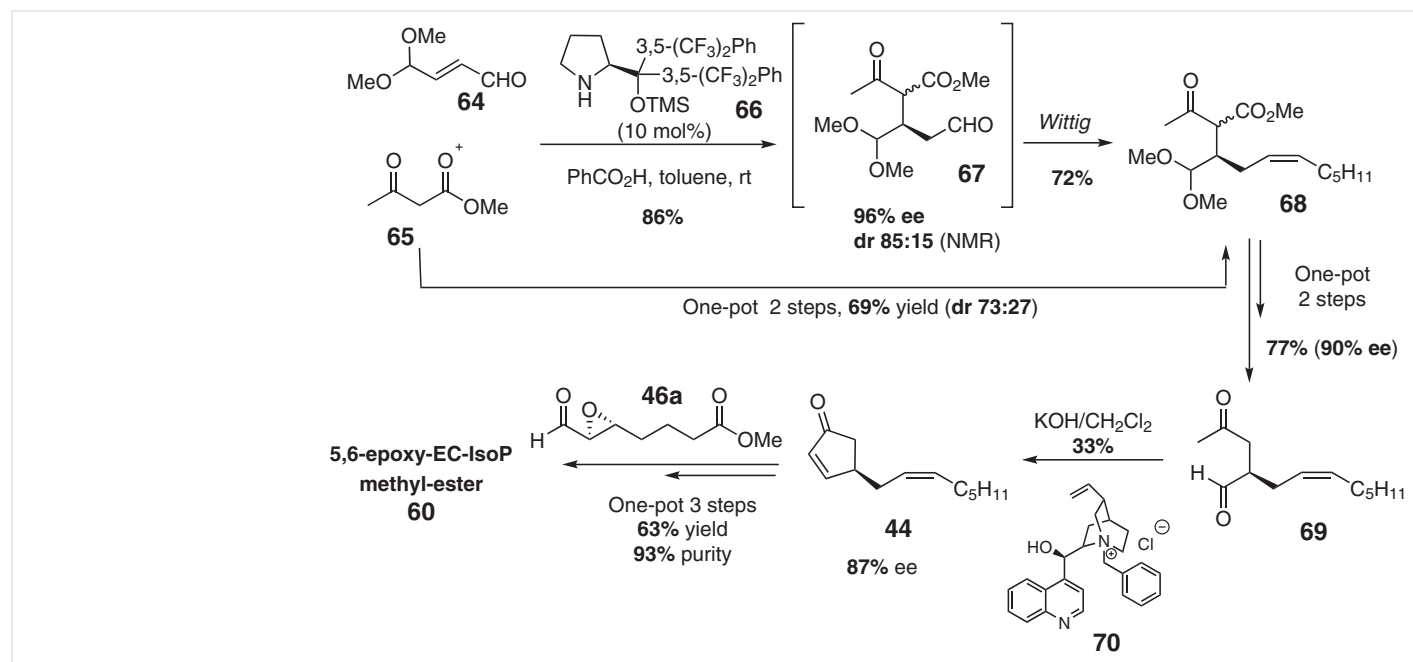

Scheme 15 Synthesis of $\mathrm{A}_{2}$-epoxy-IsoPs by the Lu and Weng group 


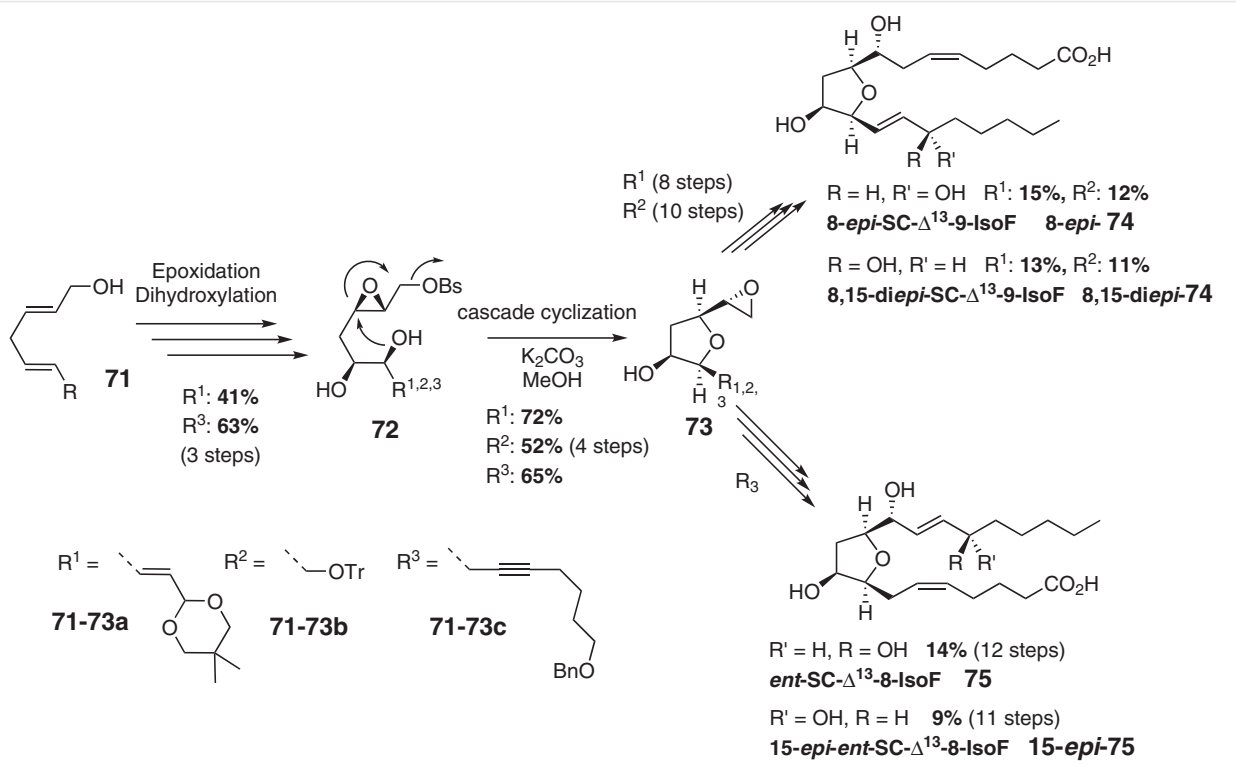

Scheme 16 Synthesis of 8,15-diepi-SC- $\Delta^{13}$-9-IsoF and ent-SC- $\Delta^{13}-8$-IsoF by the Taber group; Bs = 4-bromophenylsulfonyl

group proposed a strategy that allowed the synthesis of an alkenyl NeuroF. ${ }^{61}$ It is based on the formation of the tetrahydrofuran structure $\mathbf{7 9}$ by the desymmetrization of an achiral meso-diol $\mathbf{7 8}$ through a Tsuji-Trost reaction (Scheme 17). Indeed, a palladium-catalyzed asymmetric allylic cyclization is efficient to construct the tetrahydrofuran core ring of both the AC and ST series by playing with the chirality and the bulkiness of the ligand employed. The lateral chains are introduced by Julia and Wittig olefinations allowing freedom to insert different side chain structures. Although this approach is suitable to synthesize sensitive structures as demonstrated with the synthesis of a NeuroF, it only allows the synthesis of alkenyl structures.

Pursuing our effort in oxylipin synthesis, our group developed two divergent strategies to access the maximum number of various isofuranoid structures (Scheme 18), 21,22 with an interest in targeting PUFAs other than AA or DHA. Both strategies gave access to alkenyl and enediol families of isofuranoids by regioselective protections and cycliza- tions for the first strategy, ${ }^{22}$ with the furanic shape obtained by 5-exo-tet or 5-endo-tet intramolecular cyclizations of the hydroxy group onto an in situ prepared ortho ester. The second strategy used selective deprotections, ${ }^{21}$ after a unique Payne rearrangement of a $C_{2}$-symmetric bisepoxy alcohol followed by a 5-exo-tet intramolecular cyclization. Each strategy used a common intermediate $\mathbf{8 4}$ or $\mathbf{8 6}$ accessible on gram scale.

In the first strategy, the shared intermediate $\mathbf{8 7}$ was obtained in a seven-step sequence in $33 \%$ global yield (Scheme 19 ). Regioselective hydroxy group protection of $\mathbf{8 7}$ was performed on the $\alpha$ - or $\beta$-position of the ethyl ester. The use of Kusumoto conditions ${ }^{62}$ led to a moderate regioselectivity $(1: 4, \alpha / \beta)$ which was successfully shifted to give $\mathbf{8 8}$ as only the $\beta$-regioisomer in the following acetonide deprotection step by a simple treatment with sodium hydrogen carbonate. This observation thus led us to develop a new synthetic methodology for the regioselective monoprotection of vicdiols. ${ }^{63}$ Notably, it was shown that although kinetic control

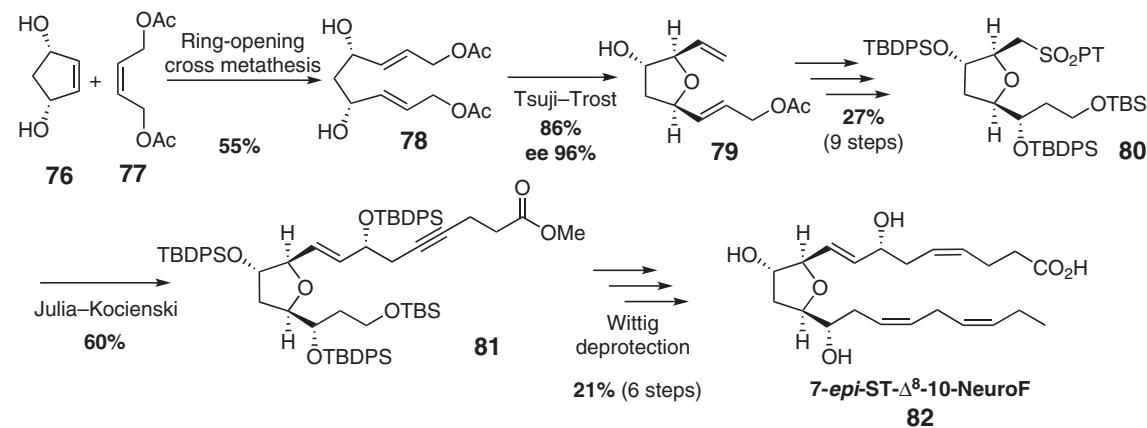

Scheme 17 Synthesis of 7-epi-ST- $\Delta^{8}-10-$ NeuroF by the Zanoni group; $\mathrm{SO}_{2} \mathrm{PT}=1$-phenyl-1H-tetrazol-5-ylsulfonyl 


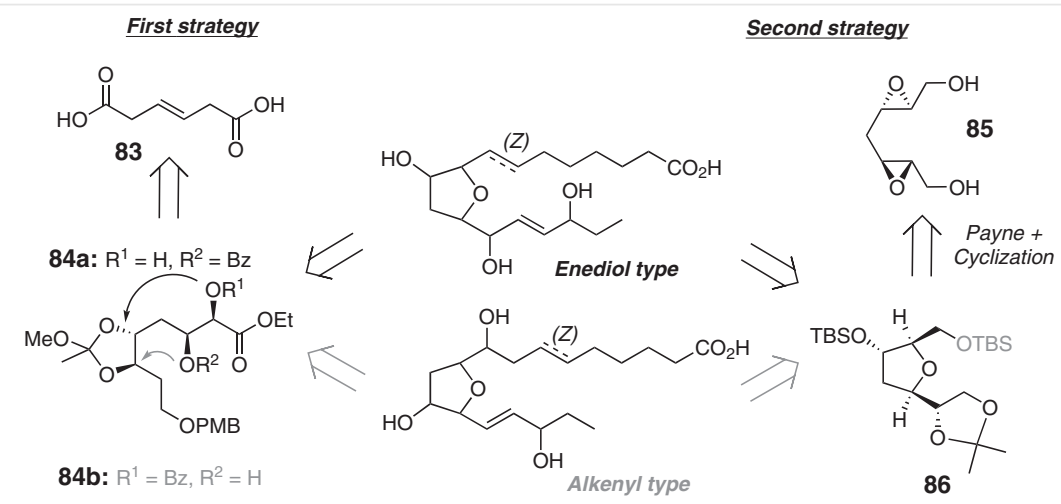

Scheme 18 Synthetic strategies towards isofuranoids by the Durand, Galano, and Oger group

in a vic-diol regioselective benzoylation favored the reaction of the most acidic hydroxy function, the other regioisomer could be obtained by 1,2-benzoyl shift in slightly basic conditions. The regioselective benzoylation on the $\alpha$-position of intermediate 87 proceeded under classical benzoylation condition and under kinetic control, leading to compound 91 after deprotection of the acetonide. The cyclization step was performed using a sequence developed by Borhan, ${ }^{64}$ which includes the in situ preparation of an ortho ester, followed by a Lewis acid induced cyclization. Cyclic compound $\mathbf{8 9}$ was obtained in $60 \%$ yield and permitted the completion of the synthesis of the first dihomo-IsoF (derivative of adrenic acid not known at the time) of the alkenyl type in 12 more steps and $12 \%$ yield. ${ }^{22}$ During the cyclization step of the intermediate $\mathbf{9 1}$ an uncontrolled partial cleavage of the PMB ether was observed and we took advantage of this and performed the cyclization and the acetonide cleavage to give $\mathbf{9 2}(\mathrm{R}=\mathrm{H})$ in a one-pot operation in decent yield. Starting from this new intermediate, the synthesis of a dihomo-IsoF from the enediol family was realized in 10 more steps and $15 \%$ yield. ${ }^{65}$ By reprotecting the primary alcohol as a PMB ether, a more complex structure of isofuranoid was synthesized, including a sensitive triene on $\omega$ chain, and the first NeuroF from the enediol family was thus obtained in 13 steps and $15 \%$ yield..$^{65}$

In our second strategy, the common intermediate $\mathbf{8 6}$ was composed of a trisubstituted tetrahydrofuran with orthogonal protecting groups to hide the functionality for the construction of the lateral chains (Scheme 20). ${ }^{21}$ This intermediate 86 was obtained from commercially available but2-yne-1,4-diol (95) in seven steps and on multigram scale albeit in a low $7 \%$ yield. The first four steps from $\mathbf{9 5}$ led to a $\mathrm{C}_{2}$-symmetric epoxide $\mathbf{8 5}$ with $95 \%$ ee thanks to L-(+)-diethyl tartrate induced Sharpless bis-epoxidation. ${ }^{66}$ We imagined for the next steps an original double Payne rearrangement ${ }^{67}$ followed by a 5 -exo-tet cyclization on the $C_{2}$ symmetric bis-epoxide 85 to give tetraol 96a. However, it is believed that one Payne rearrangement proceeded (or a di- rect attack onto the epoxide of the hydroxide ion) prior to the 5-exo-tet cyclization leading to tetraol 96b in 65\% yield and a $4: 1$ diastereomeric ratio (the other diastereomer is believed to be the result of the attack on the other side of the epoxide). A small amount of double Payne rearrangement product was isolated as a byproduct of the reaction; however, under basic conditions the cyclization, surprisingly, did not proceed, and partial decomposition into unidentified polar compounds was observed. Starting from tetraol $\mathbf{9 6 b}$, the vicinal diol was protected as an acetonide and the remaining hydroxy groups were protected as silylated ethers to give compound $\mathbf{8 6}$. X-ray crystal structure analysis of the acetonide intermediate confirmed the stereochemistry of the major diastereomer and thus the Payne/cyclization route taken by bis-epoxide $\mathbf{8 5}$.

Starting from the common intermediate $\mathbf{8 6}$, three total syntheses of isofuranoids were realized (Scheme 21). The orthogonal protection of the hydroxy groups in compound $\mathbf{8 6}$ permitted us to choose the order of insertion of the lateral chains. Thus, when deprotecting the acetonide using Rychnovsky's three-step sequence, ${ }^{68}$ the primary alcohol of the vicinal diol was free and the secondary alcohol was protected as the 1-methylcyclopropyl ether, allowing the insertion of the upper chain (here the $\alpha$-chain) prior to the $\omega$ chain. The first synthesis of an alkenyl-phytofuran (PhytoF 98) was thus accomplished in 10 more steps albeit in poor yield resulting from unexpected Dess-Martin oxidation problems. ${ }^{69}$ For the second synthesis, the tert-butyldimethylsilyl ether was selectively deprotected on the primary position of compound $\mathbf{8 6}$ in order to install the upper chain (here $\alpha$-chain) prior to the acetonide selective opening giving compound 99 which gave access to PhytoF 100 of the enediol family, in 13 steps from intermediate $\mathbf{8 6}$ and $9 \%$ yield. ${ }^{21}$ Finally, the same route was used towards the synthesis of another enediol-PhytoF 102, this time by insertion of the $\omega$-chain first and $\alpha$-chain at the end of the synthesis. ${ }^{69}$ During this synthetic pathway, Corey-Bakshi-Shibata reduction was used in order to obtain pure epimers at $\mathrm{C}$. 


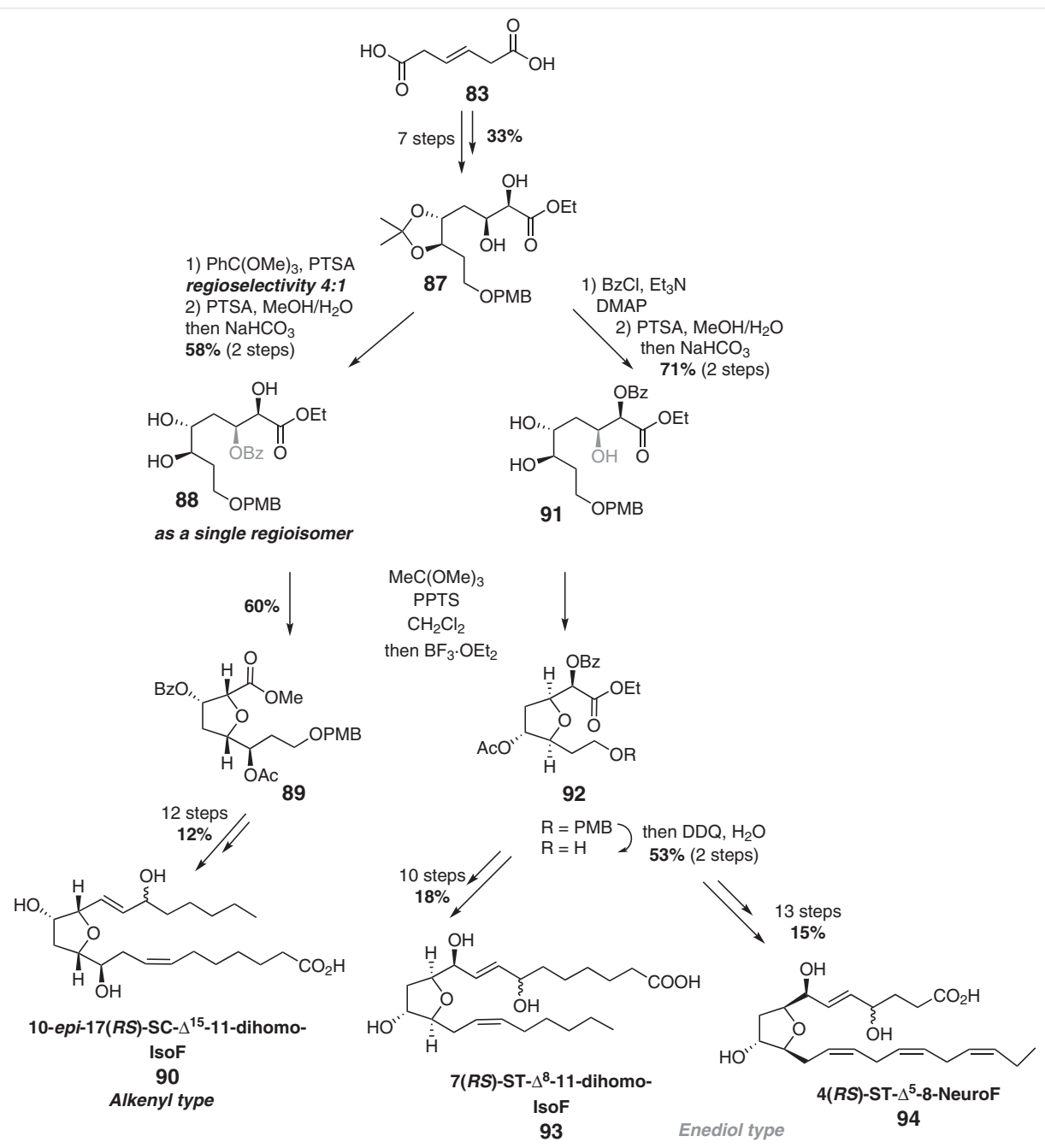

Scheme 19 Synthesis of enediol and alkenyl isofuranoids from the first strategy of the Durand, Galano, and Oger group
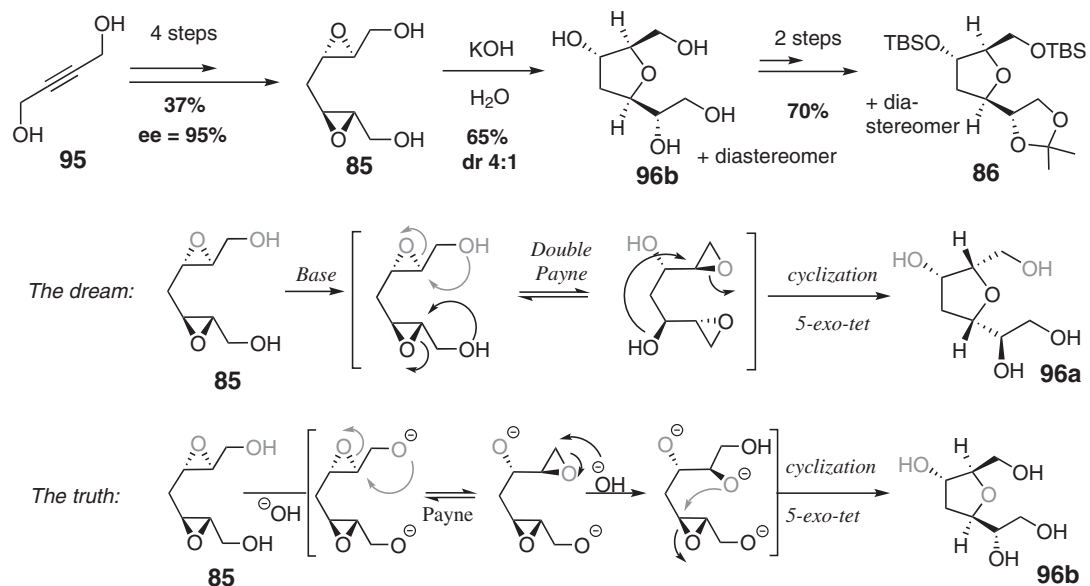

Scheme 20 Synthesis of the shared intermediate of the second strategy of the Durand, Galano, and Oger group 


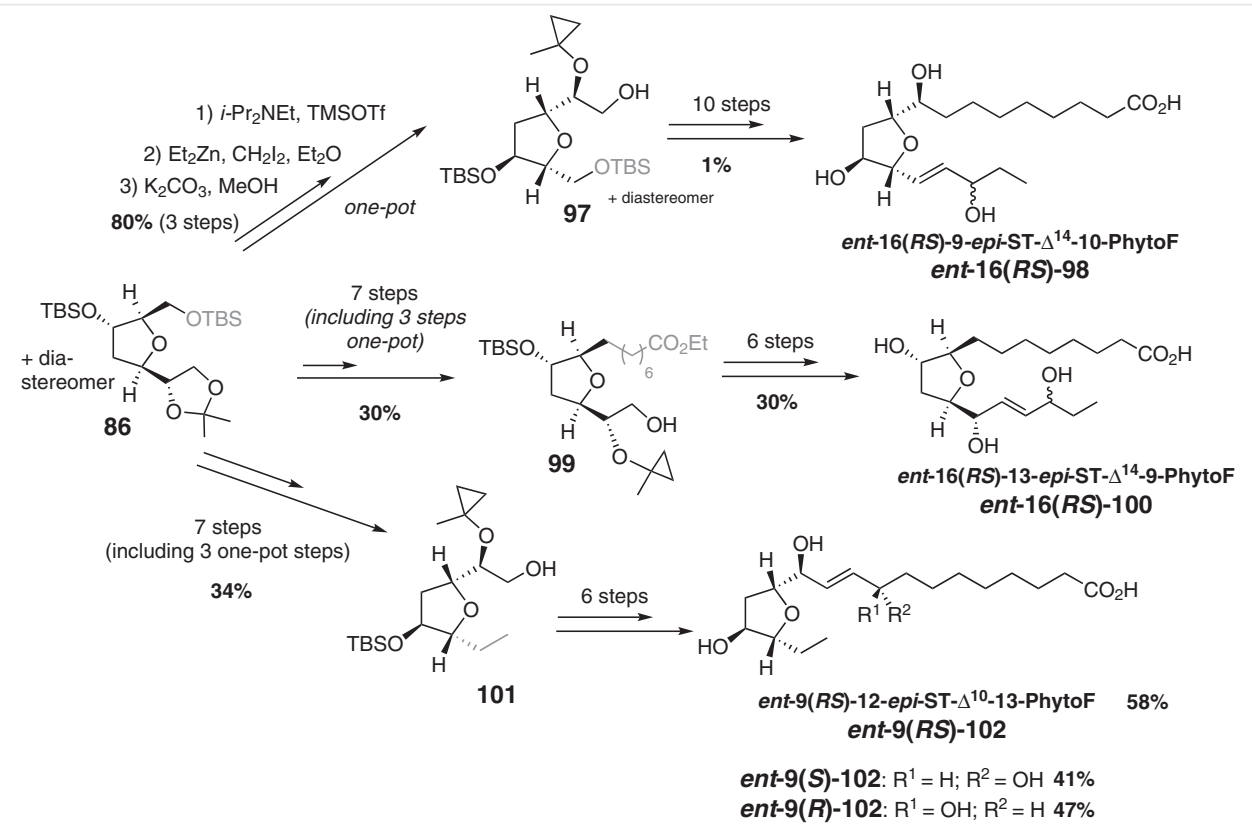

Scheme 21 Syntheses of enediol and alkenyl phytofurans by the Durand, Galano, and Oger group

To date these are the first examples of the powerful Rychnovsky's selective deprotection of acetonide applied to total synthesis.

\subsection{Isoketals}

Compared to isoprostanoids and isofuranoids, the construction of isoketals appears to be relatively simple from a synthetic point of view as their structure is linear and present only three stereogenic centers (Scheme 3). However, these PUFA derivatives possess extremely sensitive functions that make the target molecules dramatically hard to isolate and conserve in pure form. Indeed, the 1,4-ketoaldehyde is highly electrophilic as the isoketal reacts within minutes with primary amines via a Paal-Knorr condensation to provide a pyrrole ring even in buffered solutions (Scheme 3). ${ }^{25}$ The two stereogenic centers next to the carbonyl functions can readily racemize under acidic or basic conditions. Moreover, the $\beta, \gamma$-unsaturated aldehyde (or ketone) is extremely sensitive as it may easily go through conjugation or conjugation/dehydration of the allylic hydroxy group. Two groups attempted these synthetic challenges, the Salomon group in the late 1990s and the Durand, Galano, and Oger group in 2016.

The Salomon group reported the synthesis and biological investigations of two IsoKs and one NeuroK, ${ }^{70-72}$ and employed the same synthetic strategy (Scheme 22). For the global strategy, they planned to unmask the extremely sensitive aldehyde function by a mild oxidative cleavage of a vicinal diol in the final step of the synthesis. The central core of isoketals would be built by a 1,4-addition of vinylcyanocuprate to $\gamma$-alkoxyenone 106, obtained by alkylation of 1-(diethoxyphosphoryl)acetone $\mathbf{1 0 3}$ with allyl or alkyl bromide 104 and subsequent Horner-Wadsworth-Emmons olefination with isopropylidene-D-glyceraldehyde $\mathbf{1 0 5}$.

The key Michael acceptors 106a,b were formed in two steps from phosphonate $\mathbf{1 0 3}$ by deprotonation and alkylation with the corresponding halogenated compounds 104a,b, followed by HWE olefination with aldehyde 105 (Scheme 22). The $E / Z$ ratio of compounds $\mathbf{1 0 6}$ a,b varied from $4: 1$ to $8: 1$ and the yields were moderate (35-65\%). Thus, vinylstannanes $\mathbf{1 0 7 a}, \mathbf{b}$, previously synthesized, were transmetalated using $\mathrm{CuCN} / \mathrm{MeLi}$ couple to form a mixed higher order vinylcyanocuprates needed for the key 1,4-addition step. Unfortunately, this step gave rise to a mixture of diastereomers in every synthesis developed by the group, from 1:1 to 1:1.6 cis/trans ratio, not really in favor of the cis relative configuration desired for the isoketal metabolites. Fortunately in all cases these two diastereomers (cis/trans) were separable by flash column chromatography. At this stage, the final deprotections were realized. For the synthesis of the $12(R S)-\mathrm{E}_{2}$-IsoK $\mathbf{1 0 9}$ they used a saponification step for the cleavage of the ethyl ester, and unfortunately starting from pure cis-diastereomer, this step led to an epimerization and a mixture of cis/trans isomers in 2:1 ratio. The purity of the $12(R S)-\mathrm{E}_{2}$-IsoK was estimated by NMR at $50 \%$ mostly because of the diastereomer mixture.

In their next synthesis, to access to $5(R S)-\mathrm{D}_{2}$-IsoK $\mathbf{1 1 0}$, they decided to mask the acid functional group as a protected primary alcohol. Thus, starting from the mixture of diastereomers $\mathbf{1 0 8 b}$, this plan worked well for the deprotection of the alcohol (cis/trans ratio remains the same 1:1.6), and after Swern oxidation the cis-diastereomer was separated by column chromatography from its trans form. 


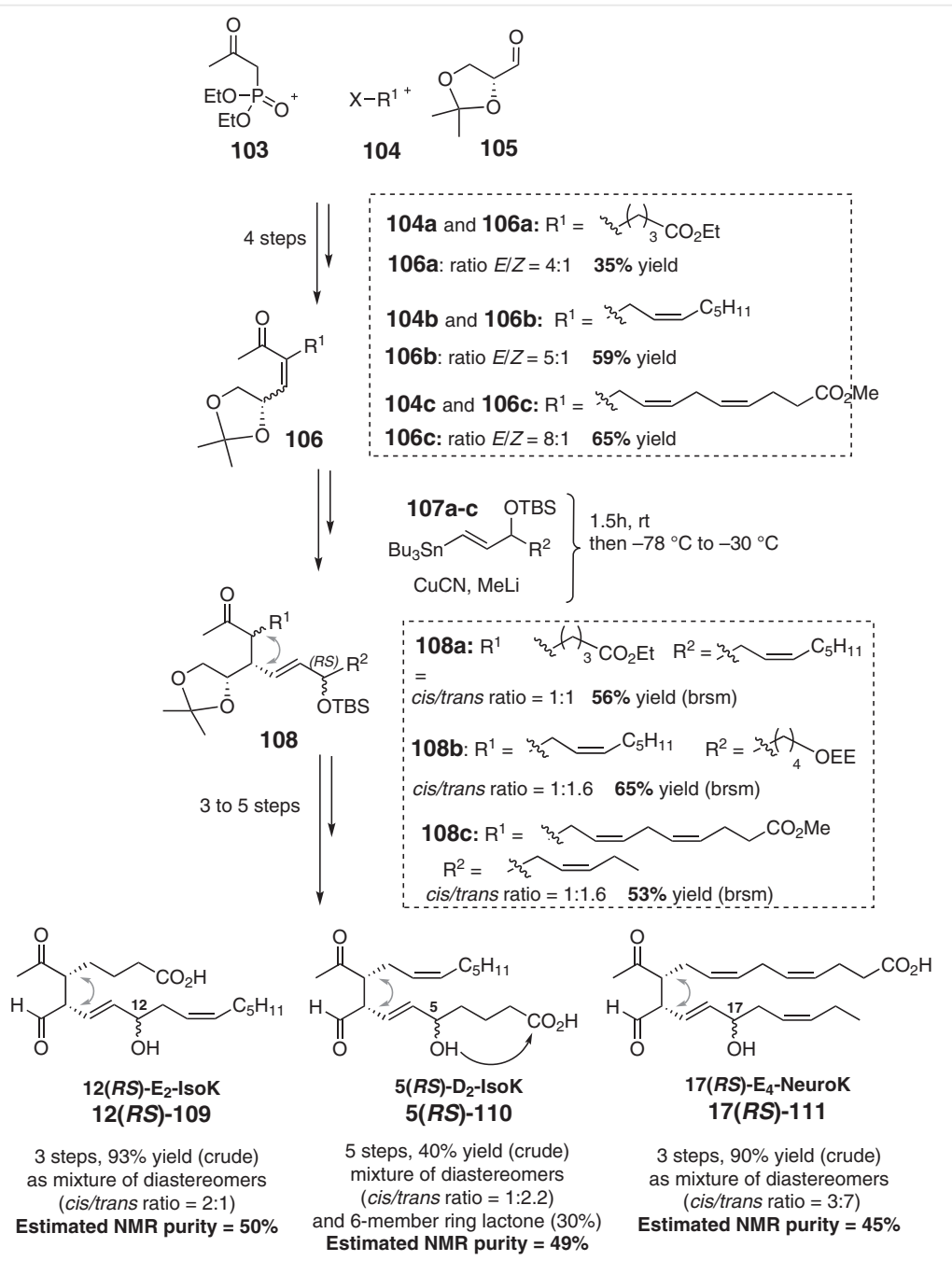

Scheme 22 Synthesis of IsoKs and NeuroK by the Salomon group

Sadly, the final oxidation step using $\mathrm{NaClO}_{2}$ led to a mixture of cis/trans isomers in 1:2.8 ratio. As if one trouble was not enough, in the process of acetonide deprotection and oxidative cleavage, they noticed the formation (30\% yield) of a six-membered-ring lactone coming from the lactonization between the acid function and the allylic alcohol at $\mathrm{C} 5$. Finally, the synthesis of the $5(R S)-\mathrm{D}_{2}$-IsoK 110 was achieved with an estimated purity of $49 \%$ (by NMR) due to the cis/trans isomers (1:2.2 ratio) and the presence of the lactone.

Finally, the Salmon group reported a synthesis that was a real synthetic challenge by choosing a neuroketal, including more sensitive bis-allylic system on the lateral chain in addition to the previously described potential troubles. The strategy remained the same using halogenated precursor $104 c$ and the vinylstannane 107c. The diastereoselectivity of the HWE reaction was improved to an $E / Z$ ratio of $8: 1$ for the preparation of $\gamma$-alkoxyenone 106c, albeit with a low diastereoselectivity for the 1,4-addition step leading to cis/trans ratio of $1: 1.6$ and a moderate yield. The synthesis of the $17(R S)-\mathrm{E}_{4}$-NeuroK $\mathbf{1 1 1}$ was achieved after hydrolysis of the methyl ester, acetonide deprotection, and oxidative cleavage with conservation of the cis/trans diastereomeric ratio (ca. 3:7) and with an estimated purity of the NeuroK of $45 \%$.

In order to clearly prove the presence of the target molecule, mass experiments were realized, and for this purpose the crude mixtures of the IsoKs and NeuroK were derivatized (Scheme 23). The compounds were first treated with methoxylamine hydrochloride in pyridine to furnish the stable corresponding bis-methoximes, which was followed by the conversion of the acid moiety into the pentafluorobenzyl ester. Scheme 23 depicts the preparation of the derivatized compound of $5(R S)-\mathrm{D}_{2}$-IsoK 110 (in mixture with its lactone form). Thanks to this mass analysis, the structure of the compound was unambiguously assigned. 

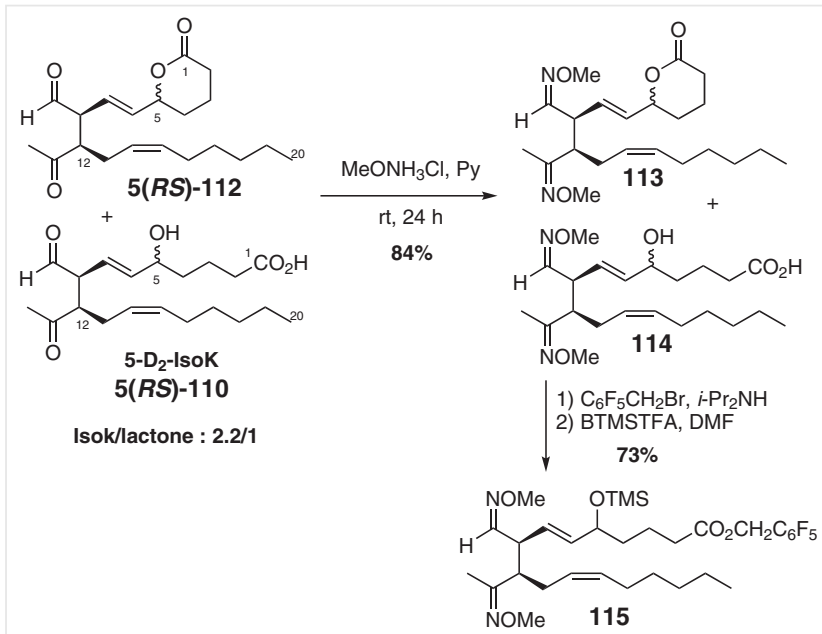

Scheme 23 Derivatization of 5- $\mathrm{D}_{2}$-IsoK and its lactone for mass experiments; BTMSTFA = bis(trimethylsilyl)trifluoroacetamide

In 2005, Roberts and co-workers reported what they have called a simplified synthesis of racemic diastereomers of $\mathrm{E}_{2}$-IsoK, particularly the $12(R S)-\mathrm{E}_{2}$-IsoK $109 .^{73}$ The strategy is the same as that developed by Salomon with the only difference residing in the protecting group of the glyceraldehydes 105, as a dimethyl acetal instead of an acetonide, together with slight changes for the final deprotections. The $12(R S)$ - $\mathrm{E}_{2}$-IsoK 109 obtained at the end is in a 1:1 mixture with the trans-isomer (also named as levuglandin LG), with a purity of $60 \%$.
The last synthetic strategy for isoketal metabolites to be discussed was realized by the Durand, Galano, and Oger group in $2016 .{ }^{74}$ The strategy differs from that of the Salomon group and involves an organocatalyzed 1,4-addition for the formation of a pivotal intermediate ready to install the two lateral chains by Wittig and HornerWadsworth-Emmons olefinations. The sensitive aldehyde and ketone functions are also uncovered later in the synthesis and mild conditions were used.

The synthesis of pivotal intermediate 121 (Scheme 24) started with the organocatalyzed Michael addition between aldehyde 117 and nitroolefin 116 using JørgensenHayashi's catalyst 118 ( 5 mol\%), and proceeded in $97 \%$ yield with 3:1 diastereomeric ratio and $90 \%$ ee. A further three steps permitted installation of the methyl group without epimerization at C9, prior to the conversion of the nitro group into carboxylic acid ${ }^{75}$ which underwent a lactonization to furnish lactone $\mathbf{1 2 0}$ as the trans-isomer only after a full epimerization initiated by a catalytic amount of DBU. Thanks to this step, the undesired diastereomer was easily recycled and this overcame the low diastereoselectivity of the first Michael addition without loss of material. A further three steps allowed the preparation of an orthogonally protected intermediate $\mathbf{1 2 1}$ in 52\% yield and only two purifications by silica gel. Thanks to this skeleton, the syntheses of different IsoK metabolites are possible. We then decided to perform the synthesis of the 5 - $\mathrm{D}_{2}$-IsoK $\mathbf{1 1 0}$.

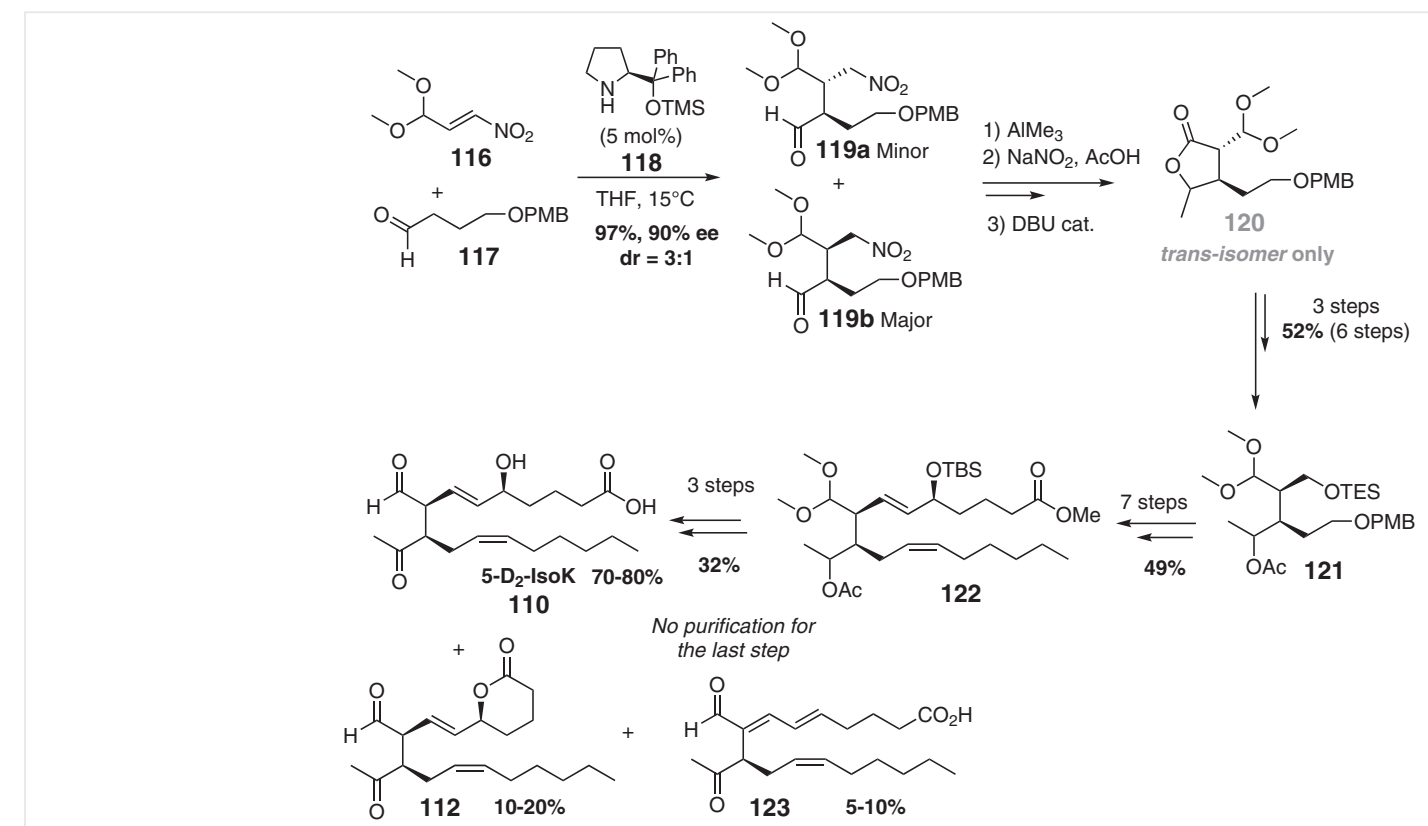

Scheme 24 Synthesis 5- $\mathrm{D}_{2}$-IsoK by the Durand, Galano, and Oger group 
The next steps were dedicated to the insertion of the lateral chains by Wittig and HWE reactions with classical chemistries. A non-diastereoselective Luche reduction gave access to the allylic alcohol function at the C5 position in an $S / R$ ratio of $3: 1$ and as the single $S$ epimer after column chromatography. Thus, the always critical deprotection steps in IsoK synthesis were realized, starting from saponification $(\mathrm{LiOH})$ of both methyl ester and acetate group, followed by Dess-Martin oxidation to obtain the methyl ketone, prior to a fluorinated deprotection of the TBS ether. The final deprotection of the dimethyl acetal was realized under acidic conditions, and after several attempts, acetic acid/water at $15{ }^{\circ} \mathrm{C}$ for five hours gave the best outcome. Unfortunately, and as described by the Salomon group, we also formed the six-membered-ring lactone 112, together with elimination product $\mathbf{1 2 3}$. However, these conditions are reproducible and avoid any purification thus limiting the formation of side products. Altogether, $5-\mathrm{D}_{2}$-IsoK was obtained in 70-80\% yield along with 10-20\% of lactone 112 and $5-10 \%$ of elimination product 123 . It should be mentioned that no LG isomer was formed in this strategy.

Thanks to this strategy, the Durand, Galano, and Oger group also prepared two other metabolites derived from EPA and DHA. ${ }^{76}$ Having in hand sensitive compounds, we decided to stop the synthesis before the final step and store the compounds. We thus developed a sub-micromolar scale procedure to realize the final deprotecting step, a step which can be performed by biologists or clinicians to obtain the desired IsoK metabolite just before use.

On the margins of this review, the Salomon group confirmed by total synthesis the earlier formation of (iso)levulinic acid hydroxylactone, ${ }^{77}$ suggesting that isoketals or levuglandins can accumulated enough to be catabolized into metabolites before reacting with proteins. A new adventure for organic chemists surely!

\section{The Discoveries Behind the Synthesis}

The numerous syntheses of PUFA metabolites realized since 2008 reflect the interest those oxylipins gained in biology and analysis. Usually, biological discoveries precede syntheses, as if chemists need a justification for their work. Nowadays, the synthetic challenge is sufficient to motivate chemists towards syntheses and sometime helps the clinicians searching for new biomarkers, or biologists searching for new targets. The last part of this review will be dedicated to a concise and partial presentation of the recent discoveries related to the new syntheses of PUFA metabolites.

\subsection{Recent Identification and Biomarkers Roles of Isoprostanes and Isofurans}

Thanks to total synthesis, new PUFA metabolites have been highlighted in vivo. The main PUFAs studied over the years have been $\alpha$-linolenic acid (ALA), arachidonic acid (AA), and docosahexaenoic acid (DHA) prior to eicosapentanoic acid (EPA). When they were first discovered in the 1990s, the isoprostanoids of these PUFAs were well described. However, among all PUFA, adrenic acid (AdA) was less known but has become of great interest in recent years, notably because this PUFA is linked to the white matter of the brain, especially the myelin, where AdA appears in high amount during the myelinization process. If oxidative stress rises during this step, AdA can be metabolized into isoprostanoids named dihomo-IsoPs or isofuranoids called dihomo-IsoFs. These metabolites can then be used as oxidative stress biomarkers. After the discovery of dihomo-IsoPs by VanRollins and co-workers ${ }^{18}$ in 2008 and thanks to the syntheses of dihomo-IsoPs by the Durand, Galano, and Oger group, ${ }^{37}$ the dihomo-IsoPs were highlighted in the plasma of patients with Rett syndrome (RTT) together with the clinicians team lead by Claudio De Felice in Italy. ${ }^{78 a}$ Rett syndrome is a rare genetic neurodevelopmental disease affecting girls as it comes from a mutation a X-linked protein. The study shows for the first time that the amount of dihomoIsoPs increases in the plasma of the Rett girls at the first stage of the disease when no clinical signs can be effective for detection (but only genetic analysis). This early study, and others since confirmed that dihomo-IsoPs are early biomarkers of Rett disease, and highlighted the role of oxidative stress as early stage of the disease. ${ }^{78 b}$

Since the phytoprostane metabolites coming from ALA which were discovered at the end of the 1990s, it has taken more than 15 years until 2015 to discover a new class, the phytofuran. ${ }^{21}$ ALA is the major PUFA in the plant kingdom and is of major interest for food sciences. The identification of such metabolites was realized for the first time in seeds and nuts. ${ }^{21}$ More recently, their presence and variation in rat liver tissues fed with an enriched diet in ALA (flax seed oil or flax seeds) or not was also confirmed, showing the relevance of ALA oxidation in tissues. ${ }^{69}$

A similar approach was initiated by the Durand, Galano, and Oger group and Dr J. C.-Y. Lee from Hong-Kong regarding the isofuranoids coming from AdA. In 2014, they reported that the excessive presence of dihomo-IsoFs in the brain of pre-term piglets suggesting the importance of such metabolites in oxidative stress impairment conditions. ${ }^{22}$ In 2015, a second proof of the relevance of dihomo-IsoFs in vivo was shown after quantification of other dihomo-IsoFs in the brain and heart of rats. ${ }^{65}$ 


\subsection{Biological Properties}

The synthesis of PUFA metabolites also permits new biological properties to be found and/or confirmed. This part of the review, in a non-exhaustive fashion, aims to briefly present the recent discoveries behind the syntheses.

\subsubsection{Phytoprostanes, Isoprostanes, and Neuropros- tanes}

In 2014, the Minghetti group studied PhytoPs derived from ALA, and more especially the types B and $L$ recently synthesized. ${ }^{41}$ They showed that the $\mathrm{B}_{1}$-PhytoPs protected immature neurons against oxidative stress in vitro and also promote the differentiation between oligodendrocyte progenitors by activating the peroxisome proliferator-activated receptor- $\gamma$ (PPAR- $\gamma$ ) receptors. ${ }^{79}$ This study showed novel mechanisms involving PPAR- $\gamma$ that can specifically affect immature brain cells, which confers neuroprotection against oxidant injury and promotes myelination, a major developmental step for the brain.

The IsoP coming from the oxidative metabolization of EPA also showed recent biological properties when regulating the release of excitatory neurotransmitters in isolated bovine retina. It should be mentioned that the release of neurotransmitters, such as aspartate in retina, is the cause of neuropathy. Thus, the pharmacological action of 5-epi-5$\mathrm{F}_{3 \mathrm{t}}$-IsoP, when inhibiting $\mathrm{K}^{+}$-evoked $\left[{ }^{3} \mathrm{H}\right] \mathrm{d}$-aspartate release in a concentration-dependent manner, with a maximum inhibition ca. $47 \%$ at $0.1 \mu \mathrm{M}$, is of great interest.

In recent years DHA has appeared as the best source of cardioprotective omega- 3 by acting on ion channels. However, in 2003 Le Guennec and co-workers showed that DHA itself is less potent on ion channels than oxidized DHA. ${ }^{80}$ Indeed, a complete study was realized at the University of Montpellier, showing that the oxidized DHA has anti-arrhythmic properties by reducing the number of arrhythmic events in vivo. Nonetheless, the same activity was found for one isolated NeuroP coming from DHA peroxidation, $4(R S)$ $\mathrm{F}_{4 \mathrm{t}}$-NeuroP, which lowers in a concentration dependent fashion the number of arrhythmic events with a maximum of $86 \%$ at $100 \mathrm{nM} .^{12}$ This work also highlighted a new mechanism of action of the NeuroP involving ryanodine receptors.

\subsubsection{Epoxy-isoprostanes}

Epoxy-isoprostanes, and more especially the E-type linked to phosphocholine, were identified in atherosclerotic lesions where they activate inflammatory responses. ${ }^{81,82}$ However, it was also shown that the phospholipid derivatives can be hydrolyzed to release the free acid by phospholipase $\mathrm{A} 2$, and also have potent biological activities. ${ }^{44}$ In $2014 / 2105$, in relation with their synthesis of epoxy-IsoPs and derivatives, the Carreira group showed that the 5,6-epoxy-IsoPs type $\mathrm{A}$ and $\mathrm{E}$ have potent anti-inflammatory activities. ${ }^{49,83}$ Indeed, they are able to inhibit the secretion of pro-inflammatory cytokines such as interleukine 6 (IL-6) and interleukine 12 (IL-12). A very interesting finding of this study was that the C5-six-membered-ring lactone (a potential metabolite, see Scheme 14) of the A-epoxy-IsoP has shown a higher anti-inflammatory activity than the free acid form.

\section{Conclusion}

This review was first designed for the community of organic chemists to introduce cyclic non-enzymatic metabolites of PUFA as targets of great interest. The content of the manuscript is comprehensive when presenting the origins of the compounds, their structures and nomenclatures, prior to the more detailed work on their total synthesis. It is hoped that this review is a useful tool for synthetic chemists wishing to start working on PUFA metabolites, as well as all scientists in the area of PUFA.

\section{Abbreviations and Acronyms}

\author{
AA Arachidonic acid \\ AdA adrenic acid \\ ALA $\alpha$-Linolenic acid \\ Dihomo-IsoF Dihomo-isofuran \\ Dihomo-IsoK Dihomo-isoketal \\ Dihomo-IsoP Dihomo-isoprostane \\ DHA Docosahexaenoic acid \\ DPA Docosapentaenoic acid \\ EC Epoxy-IsoPs type A \\ EI Epoxy-IsoPs type E \\ EPA Eicosapentaenoic acid \\ Epoxy-IsoP Epoxy-isoprostanes \\ IsoF Isofuran \\ IsoK Isoketal \\ Isoprostane IsoP \\ Lyso-PC Lysophosphatidylcholine \\ NeuroF Neurofuran \\ NeuroK Neuroketal \\ NeuroP Neuroprostane \\ PECPC 1-palmitoyl-2-(5,6-epoxyisoprostane-A2)-sn- \\ glycero-3-phosphatidylcholine \\ PEIPC 1-palmitoyl-2-(5,6-epoxyisoprostane-E2)-sn- \\ glycero-3-phosphatidylcholine \\ PhytoF Phytofuran \\ PhytoK Phytoketal \\ PhytoP Phytoprostane \\ PUFA Polyunsaturated Fatty Acid
}




\section{References}

(1) Morrow, J. D.; Hill, K. E.; Burk, R. F.; Nammour, T. M.; Badr, K. F.; Roberts, L. J. II. Proc. Natl. Acad. Sci. U.S.A. 1990, 87, 9383.

(2) Jahn, U.; Galano, J.-M.; Durand, T. Angew. Chem. Int. Ed. 2008, 47, 5894.

(3) Nugteren, D. H.; Vonkeman, H.; van Dorp, D. A. Recl. Trav. Chim. Pays-Bas 1967, 86, 1237.

(4) Pryor, W. A.; Stanley, J. P. J. Org. Chem. 1975, 40, 3615.

(5) Porter, N. A.; Funk, M. O. J. Org. Chem. 1975, 40, 3614.

(6) Morrow, J. D.; Harris, T. M.; Roberts, L. J. II. Anal. Biochem. 1990, $184,1$.

(7) Milne, G. L.; Yin, H.; Hardy, K. D.; Davies, S. S.; Roberts, L. J. II. Chem. Rev. 2011, 111, 5973.

(8) Yin, H.; Xu, L.; Porter, N. A. Chem. Rev. 2011, 111, 5944.

(9) Kadiiska, M. B.; Gladen, B. C.; Baird, D. D.; Germolec, D.; Graham, L. B.; Parker, C. E.; Nyska, A.; Wachsman, J. T.; Ames, B. N.; Basu, S.; Brot, N.; Fitzgerald, G. A.; Floyd, R. A.; George, M.; Heinecke, J. W.; Hatch, G. E.; Hensley, K.; Lawson, J. A.; Marnett, L. J.; Morrow, J. D.; Murray, D. M.; Plastaras, J.; Roberts, L. J. II.; Rokach, J.; Shigenaga, M. K.; Sohal, R. S.; Sun, J.; Tice, R. R.; Van Thiel, D. H.; Wellner, D.; Walter, P. B.; Tomer, K. B.; Mason, R. P.; Barrett, J. C. Free Radical Biol. Med. 2005, 38, 698.

(10) Cracowski, J.-L.; Durand, T. Fundam. Clin. Pharmacol. 2006, 20, 417.

(11) Ting, H. J.; Khasawneh, F. T. J. Biomed. Sci. 2010, 17, 24.

(12) Roy, J.; Oger, C.; Thireau, J.; Roussel, J.; Mercier-Touzet, O.; Faure, D.; Pinot, E.; Farah, C.; Taber, D. F.; Cristol, J.-P.; Lee, J. C. Y.; Lacampagne, A.; Galano, J.-M.; Durand, T.; Le, Guennec. J.-Y. Free Radical Biol. Med. 2015, 86, 269.

(13) Galano, J.-M.; Mas, E.; Barden, A.; Mori, T. A.; Signorini, C.; De Felice, C.; Barrett, A.; Opere, C.; Pinot, E.; Schwedhelm, E.; Benndorf, R.; Roy, J.; Le, Guennec. J.-Y.; Oger, C.; Durand, T. Prostaglandins Other Lipid Mediators 2013, 107, 95.

(14) Cuyamendous, C.; de la Torre, A.; Lee, Y. Y.; Leung, K. S.; Guy, A.; Bultel-Poncé, V.; Galano, J.-M.; Lee, J. C.-Y.; Oger, C.; Durand, T. Biochimie 2016, 130, 49.

(15) Salomon, R. G.; Bi, W. Antioxid. Redox Signaling 2015, 22, 1703.

(16) Imbusch, R.; Mueller, M. J. Free Radical Biol. Med. 2000, 28, 720.

(17) Lawson, J. A.; Kim, S.; Powell, W. S.; FitzGerald, G. A.; Rokach, J. J. Lipid Res. 2006, 47, 2515.

(18) VanRollins, M.; Woltjer, R. L.; Yin, H.; Morrow, J. D.; Montine, T. J. J. Lipid Res. 2008, 49, 995.

(19) Nourooz-Zadeh, J.; Liu, E. H. C.; Änggård, E. E.; Halliwell, B. Biochem. Biophys. Res. Commun. 1998, 242, 338.

(20) Fessel, J. P.; Porter, N. A.; Moore, K. P.; Sheller, J. R.; Roberts, L. J. II. Proc. Natl. Acad. Sci. U.S.A. 2002, 99, 16713.

(21) Cuyamendous, C.; Leung, K. S.; Durand, T.; Lee, J. C.-Y.; Oger, C.; Galano, J.-M. Chem. Commun. 2015, 51, 15696.

(22) de la Torre, A.; Lee, Y. Y.; Oger, C.; Sangild, P. T.; Durand, T.; Lee, J. C.-Y.; Galano, J.-M. Angew. Chem. Int. Ed. 2014, 53, 6249.

(23) Song, W.-L.; Lawson, J. A.; Reilly, D.; Rokach, J.; Chang, C.-T.; Giasson, B.; FitzGerald, G. A. J. Biol. Chem. 2008, 283, 6.

(24) Salomon, R. G.; Subbanagounder, G.; Singh, U.; O'Neil, J.; Hoff, H. F. Chem. Res. Toxicol. 1997, 10, 750.

(25) Brame, C. J.; Salomon, R. G.; Morrow, J. D.; Roberts, L. J. II. J. Biol. Chem. 1999, 274, 13139.

(26) Bernoud-Hubac, N.; Davies, S. S.; Boutaud, O.; Montine, T. J.; Roberts, L. J. II. J. Biol. Chem. 2001, 276, 30964.

(27) Bernoud-Hubac, N.; Roberts, L. J. II. Biochemistry (Moscow) 2002, 41, 11466 .
(28) Davies, S. S.; Amarnath, V.; Montine, K. S.; Bernoud-Hubac, N.; Boutaud, O.; Montine, T. J.; Roberts, L. J. II. FASEB J. 2002, 16, 715.

(29) Rokach, J.; Khanapure, S. P.; Hwang, S.-W.; Adiyaman, M.; Lawson, J. A.; FitzGerald, G. A. Prostaglandins 1997, 54, 853.

(30) Taber, D. F.; Morrow, J. D.; Roberts, L. J. II. Prostaglandins 1997, $53,63$.

(31) Taber, D. F.; Fessel, J. P.; Roberts, L. J. II. Prostaglandins Other Lipid Mediators 2004, 73, 47.

(32) Jahn, U.; Dinca, E. Chem. Eur. J. 2008, 15, 58.

(33) Jahn, U.; Dinca, E. J. Org. Chem. 2010, 75, 4480.

(34) Smrček, J.; Pohl, R.; Jahn, U. Org. Biomol. Chem. 2017, 15, 9408.

(35) Oger, C.; Brinkmann, Y.; Bouazzaoui, S.; Durand, T.; Galano, J.M. Org. Lett. 2008, 10, 5087.

(36) Oger, C.; Marton, Z.; Brinkmann, Y.; Bultel-Poncé, V.; Durand, T.; Graber, M.; Galano, J.-M. J. Org. Chem. 2010, 75, 1892.

(37) Oger, C.; Bultel-Poncé, V.; Guy, A.; Durand, T.; Galano, J.-M. Eur. J. Org. Chem. 2012, 2621.

(38) Brinkmann, Y.; Oger, C.; Guy, A.; Durand, T.; Galano, J.-M. J. Org. Chem. 2010, 75, 2411.

(39) Guy, A.; Oger, C.; Heppekausen, J.; Signorini, C.; De Felice, C.; Fürstner, A.; Durand, T.; Galano, J.-M. Chem. Eur. J. 2014, 20, 6374.

(40) Oger, C.; Bultel-Poncé, V.; Guy, A.; Balas, L.; Rossi, J.-C.; Durand, T.; Galano, J.-M. Chem. Eur. J. 2010, 16, 13976.

(41) Guy, A.; Flanagan, S.; Durand, T.; Oger, C.; Galano, J.-M. Front. Chem. 2015, 3, 41; DOI: 10.3389/fchem.2015.00041.

(42) Beretta, R.; Giambelli Gallotti, M.; Pennè, U.; Porta, A.; Gil Romero, J. F.; Zanoni, G.; Vidari, G. J. Org. Chem. 2015, 80, 1601.

(43) Vázquez-Romero, A.; Verdaguer, X.; Riera, A. Eur. J. Org. Chem. 2013, 1716 .

(44) Watson, A. D.; Subbanagounder, G.; Welsbie, D. S.; Faull, K. F.; Navab, M.; Jung, M. E.; Fogelman, A. M.; Berliner, J. A. J. Biol. Chem. 1999, 274, 24787.

(45) Jung, M. E.; Berliner, J. A.; Koroniak, L.; Gugiu, B. G.; Watson, A. D. Org. Lett. 2008, 10, 4207.

(46) Zhong, W.; Springstead, J. R.; Al-Mubarak, R.; Lee, S.; Li, R.; Emert, B.; Berliner, J. A.; Jung, M. E. J. Med. Chem. 2013, 56, 8521.

(47) Kawashima, H.; Kobayashi, Y. Org. Lett. 2014, 16, 2598.

(48) Egger, J.; Bretscher, P.; Freigang, S.; Kopf, M.; Carreira, E. M. Angew. Chem. Int. Ed. 2013, 52, 5382.

(49) Egger, J.; Bretscher, P.; Freigang, S.; Kopf, M.; Carreira, E. M. J. Am. Chem. Soc. 2014, 136, 17382.

(50) Weng, J.; Wang, S.; Huang, L.-J.; Luo, Z.-Y.; Lu, G. Chem. Commun. 2015, 51, 10170.

(51) Jung, M. E.; Berliner, J. A.; Angst, D.; Yue, D.; Koroniak, L.; Watson, A. D.; Li, R. Org. Lett. 2005, 7, 3933.

(52) Jung, M. E.; Kers, A.; Subbanagounder, G.; Berliner, J. A. Chem. Commun. 2003, 196.

(53) Acharya, H. P.; Kobayashi, Y. Angew. Chem. Int. Ed. 2005, 44, 3481.

(54) Acharya, H. P.; Kobayashi, Y. Tetrahedron Lett. 2005, 46, 8435.

(55) Acharya, H. P.; Kobayashi, Y. Tetrahedron Lett. 2004, 45, 1199.

(56) Acharya, H. P.; Miyoshi, K.; Kobayashi, Y. Org. Lett. 2007, 9, 3535.

(57) Egger, J.; Fischer, S.; Bretscher, P.; Freigang, S.; Kopf, M.; Carreira, E. M. Org. Lett. 2015, 17, 4340.

(58) Taber, D. F.; Pan, Y.; Zhao, X. J. Org. Chem. 2004, 69, 7234.

(59) Taber, D. F.; Gu, P.; Li, R. J. Org. Chem. 2009, 74, 5516.

(60) (a) Taber, D. F.; Zhang, Z.J. Org. Chem. 2006, 71, 926. (b) Taber, D. F. University of Delaware, USA. Personnal communication, 2017.

(61) Valli, M.; Bruno, P.; Sbarbada, D.; Porta, A.; Vidari, G.; Zanoni, G. J. Org. Chem. 2013, 78, 5556. 
(62) Oikawa, M.; Wada, A.; Okazaki, F.; Kusumoto, S. J. Org. Chem. 1996, 61, 4469.

(63) de la Torre, A.; Oger, C.; Bultel-Poncé, V.; Durand, T.; Galano, J.M. Synlett 2016, 27, e11.

(64) Zheng, T.; Narayan, R. S.; Schomaker, J. M.; Borhan, B. J. Am. Chem. Soc. 2005, 127, 6946.

(65) de la Torre, A.; Lee, Y. Y.; Mazzoni, A.; Guy, A.; Bultel-Poncé, V.; Durand, T.; Oger, C.; Lee, J. C.-Y.; Galano, J.-M. Chem. Eur. J. 2015, $21,2442$.

(66) Hoffmann, R. W.; Kahrs, B. C.; Schiffer, J.; Fleischhauer, J. J. Chem. Soc., Perkin Trans. 2 1996, 2407.

(67) Payne, G. B. J. Org. Chem. 1962, 27, 3819.

(68) Rychnovsky, S. D.; Kim, J. Tetrahedron Lett. 1991, 32, 7219.

(69) Cuyamendous, C.; Leung, K. S.; Bultel-Poncé, V.; Guy, A.; Durand, T.; Galano, J.-M.; Lee, J. C. Y.; Oger, C. Eur. J. Org. Chem. 2017, 2486.

(70) Subbanagounder, G.; Salomon, R. G.; Murthi, K. K.; Brame, C.; Roberts, L. J. II. J. Org. Chem. 1997, 62, 7658.

(71) Roy, S. C.; Nagarajan, L.; Salomon, R. G. J. Org. Chem. 1999, 64, 1218.

(72) Sha, W.; Salomon, R. G. J. Org. Chem. 2000, 65, 5315.

(73) Amarnath, V.; Amarnath, K.; Masterson, T.; Davies, S.; Roberts, L. J. II. Synth. Commun. 2005, 35, 397.

(74) Candy, M.; Durand, T.; Galano, J.-M.; Oger, C. Eur. J. Org. Chem. 2016, 5813.

(75) Matt, C.; Wagner, A.; Mioskowski, C. J. Org. Chem. 1997, 62, 234.
(76) Durand, T.; Galano, J.-M.; Oger, C. Université de Montpellier. Unpublished work, 2017

(77) Cheng, Y.-S.; Yu, W.; Xu, Y.; Salomon, R. G. J. Nat. Prod. 2017, 80, 488.

(78) (a) De Felice, C.; Signorini, C.; Durand, T.; Oger, C.; Guy, A.; Bultel-Poncé, V.; Galano, J.-M.; Ciccoli, L.; Leoncini, S.; D'Esposito, M.; Filosa, S.; Pecorelli, A.; Valacchi, G.; Hayek, J. J. Lipid Res. 2011, 52, 2287. (b) De Felice, C.; Della Ragione, F.; Signorini, C.; Leoncini, S.; Pecorelli, A.; Ciccoli, L.; Scalabrì, F.; Marracino, F.; Madonna, M.; Belmonte, G.; Ricceri, L.; De Filippis, B.; Laviola, G.; Valacchi, G.; Durand, T.; Galano, J. M.; Oger, C.; Guy, A.; Bultel-Poncé, V.; Guy, J.; Filosa, S.; Hayek, J.; D'Esposito, M. Neurobiol. Dis. 2014, 68, 66.

(79) Minghetti, L.; Salvi, R.; Salvatori, M. L.; Ajmone-Cat, M. A.; De Nuccio, C.; Visentin, S.; Bultel-Poncé, V.; Oger, C.; Guy, A.; Galano, J.-M.; Greco, A.; Bernardo, A.; Durand, T. Free Radical Biol. Med. 2014, 73, 41.

(80) Judé, S.; Bedut, S.; Roger, S.; Pinault, M.; Champeroux, P.; White, E.; Le Guennec, J.-Y. Br. J. Pharmacol. 2003, 139, 816.

(81) Subbanagounder, G.; Wong, J. W.; Lee, H.; Faull, K. F.; Miller, E.; Witztum, J. L.; Berliner, J. A. J. Biol. Chem. 2002, 277, 7271.

(82) Cole, A. L.; Subbanagounder, G.; Mukhopadhyay, S.; Berliner, J. A.; Vora, D. K. Arterioscler., Thromb., Vasc. Biol. 2003, 23, 1384.

(83) Bretscher, P.; Egger, J.; Shamshiev, A.; Trötzmüller, M.; Köfeler, H.; Carreira, E. M.; Kopf, M.; Freigang, S. EMBO Mol. Med. 2015, 7, 593. 